\title{
EVALUACIÓN DE LA PERCEPCIÓN SOCIAL DEL ESPACIO FLUVIAL URBANIZADO DEL ARROYO NAPOSTÁ GRANDE, BAHÍA BLANCA, ARGENTINA
}

\author{
Aldana Mastrandrea \\ Comisión de Investigaciones Científicas y Universidad Nacional del Sur \\ aldanamastrandrea@gmail.com - aldana.mastrandrea@uns.edu.ar \\ ORCID iD: https://orcid.org/0000-0001-6902-1692 \\ Guillermo Angeles \\ Universidad Nacional del Sur \\ guillermo.angeles@uns.edu.ar \\ ORCID iD: https://orcid.org/0000-0002-0187-6421 \\ Julián Olavarría \\ Universidad Nacional del Sur \\ jeolavarria@gmail.com. \\ ORCID iD: https://orcid.org/0000-0003-4349-3485
}

Recibido: 30/11/2017; Aceptado: 17/06/2019.

Cómo citar este artículo/Citation: Mastrandrea, A., Angeles, G. y Olavarría, J. (2019). Evaluación de la percepción social del espacio fluvial urbanizado del arroyo Napostá Grande, Bahía Blanca, Argentina. Estudios Geográficos, 80 (287), e017. https://doi.org/10.3989/ estgeogr.201933.013

RESUMEN: La alternancia de eventos de exceso y déficit hídrico, los efectos derivados de estos fenómenos y las intervenciones que realiza la sociedad generan diferentes problemas ambientales. La percepción que los habitantes construyen de estos inconvenientes constituye el eje central de esta investigación. Se aplican Tecnologías de la Información y Comunicación (TIC's) y Tecnologías de la Información Geográfica (TIG`s) con el objetivo de conocer la percepción social que un sector de la población de la ciudad de Bahía Blanca tiene del estado de conservación del tramo inferior del arroyo Napostá Grande, localizado en el sudoeste bonaerense y de los principales problemas que se manifiestan en el espacio fluvial. Se diseña y aplica un cuestionario telefónico cuyas respuestas se georreferencian a través de un Sistema de Información Geográfica (SIG), representan a través de los estimadores de densidad núcleo (kernel) y analizan, en función de los aportes teórico-metodológicos de la Geografía de la Percepción. A modo de resultados preliminares, se advierte que la percepción social construida del arroyo y de su espacio fluvial, difiere de acuerdo con la delegación de residencia y se manifiesta como un contraste entre un sector degradado, pero, al mismo tiempo, representativo del espacio urbano.

PALABRAS CLAVE: TIC's; TIG`s; Problemas ambientales; Geografía de la Percepción; Gestión territorial.

\section{SOCIAL PERCEPTION ASSESSMENT ON A FLUVIAL SPACE URBANIZED OF THE NAPOSTÁ GRANDE STREAM, BAHÍA BLANCA, ARGENTINA}

ABSTRACT: The alternation of excess and water deficit events, the effects derived from these phenomena and the interventions carried out by society generate different environmental problems. The perception that the inhabitants construct of these inconveniences constitutes the central axis of this investigation. Information and Communication Technologies (ICT's) and Geographic Information Technologies ( $T I G$ 's) are applied with the objective of knowing the social perception that a sector of the population of the city of Bahía Blanca has of the state of conservation of the lower section of the Napostá Grande stream, located in southwestern Buenos Aires and the main problems that manifest themselves in the fluvial space. A telephone questionnaire is designed and applied. The answers are georeferenced through a Geographic Information System (GIS), represented through the kernel density estimators and analyzed, according to the theoreticalmethodological contributions of the Geography of Perception. By way of preliminary results, it is noted that the built social perception of the stream and its river area, differs according to the delegation of residence and manifests as a contrast between a sector degraded but, at the same time, representative of the urban space.

KEY WORDS: TIC'S; TIG's; Enviromental problemas; Geography of Perception; Territorial Management 


\section{INTRODUCCIÓN}

La percepción social que las personas construyen de los problemas que se manifiestan en su vida diaria es un factor decisivo de su comportamiento, cuestión que puede intervenir en la mitigación, reducción o, por el contrario, amplificación de los problemas ambientales que se generan en la interrelación de la sociedad con la naturaleza. En este sentido, el conocimiento de la percepción social que un sector de los habitantes de la ciudad de Bahía Blanca elabora acerca del estado de conservación del tramo inferior del arroyo Napostá Grande -que atraviesa la localidad- y de los principales problemas relacionados con su dinámica constituye una información relevante para la planificación y toma de decisiones.

En este contexto, las Tecnologías de la Información y Comunicación (TIC's) constituyen valiosas herramientas tecnológicas que posibilitan localizar, analizar, gestionar y difundir información en diversos formatos. En el ámbito de las disciplinas relacionadas con la planificación y gestión del territorio, especialmente en Geografía, las TIC's han tenido gran incidencia bajo la denominación de geotecnologías o Tecnologías de la Información Geográfica (TIG`s). Estas son centro del debate que diversos autores (Dobson, 1993; Buzai, 2001; Bosque Sendra, 2001; Dodge, Kitchin, y Perkins, 2011) han desarrollado en torno al paradigma geotecnológico y a conceptos asociados como geografía global y cibergeografía. De este modo, las TIG's son un conjunto de herramientas especializadas que ayudan en la recolección, manejo y análisis espacio-temporal de datos relacionados con el territorio. Es decir, permiten asociar la representación gráfica con todos aquellos datos que se consideran de interés para estudiar distintos aspectos de la realidad que se manifiestan en el espacio, así como también su dinámica (Buzai, 2001).

Teniendo en cuenta los antecedentes conceptuales que se relacionan con el tema objeto de estudio es importante mencionar que, en el sudoeste bonaerense, son escasas las investigaciones que desde la Geografía abordan la percepción social de cuestiones ambientales a través de la utilización de geotecnologías. En el ámbito internacional, se destacan los estudios de Goodchild (2007), Alessa, Kliskey y Brown (2008), Brown y Reed (2012), Palacio Buendía (2017), Moreno Jiménez y Fuenzalida Díaz (2017), quienes utilizan técnicas de análisis espacial con TIC's y TIG's para estudiar la subjetividad de las personas en relación con diferentes problemas socialmente percibidos.
De este modo, la consideración de técnicas cuantitativas, entre las que se encuentran las estadísticas y de análisis espacial (TIC's y TIG's) y el cuestionario semi-estructurado, colaboran en la recopilación de datos, conocimiento, espacialización, evaluación y análisis de información referida a problemas socialmente relevantes.

Cabe mencionar que, el área de estudio, corresponde al tramo inferior del arroyo Napostá Grande, sector que se encuentra totalmente modificado por el proceso de urbanización. A su vez, si bien ciertos espacios se han transformado en sitios de preferencia por la población local debido al predominio de un uso del suelo recreativo, se evidencia, en determinados sectores, especialmente en los barrios que se encuentran próximos a la desembocadura del arroyo, la ausencia de un manejo integral del espacio fluvial, de allí la relevancia de realizar la presente investigación.

En este contexto, las construcciones mentales realizadas por los vecinos de la ciudad de Bahía Blanca a partir de la percepción de su espacio más próximo son elementos fundamentales de análisis. Así, por ejemplo, cada persona percibe de modo diferencial el estado del arroyo Napostá Grande, los principales problemas relacionados con el mismo, tales como eventos de inundaciones, anegamientos y/o desbordes del arroyo, presencia de residuos domiciliarios e industriales, inadecuado mantenimiento y limpieza y conflictos sanitarios, entre otros, en función de diversos aspectos. En suma, las concepciones elaboradas por los habitantes del espacio urbano del sector estudiado constituyen una información valiosa para realizar un diagnóstico de la percepción social que tienen del estado de conservación del arroyo Napostá Grande. Esto permite identificar y espacializar, mediante cartografías detalladas, los principales inconvenientes percibidos, aspectos que colaboran en la toma de decisiones para llevar a cabo un manejo sustentable del espacio fluvial a través de una visualización integral de las necesidades de la población local.

Desde esta perspectiva, el objetivo del presente trabajo es conocer la percepción social que un sector de la población de la ciudad de Bahía Blanca tiene del estado de conservación del sector inferior del arroyo Napostá Grande, localizado en el sudoeste bonaerense, y de los principales problemas que se manifiestan en el espacio fluvial. Para ello, se recurre a la aplicación de técnicas cuantitativas, herramientas que resultan de gran utilidad para recopilar, espacializar y analizar información referida a la percepción social de diferentes fenómenos que ocurren en el espacio 
vivido por los habitantes. Su conocimiento constituye una necesidad principal debido a que posibilita plantear acciones futuras, a través de la evaluación de la subjetividad de las personas, con respecto al arroyo, a su espacio fluvial y a su localización espacial.

\section{CONTEXTO TEÓRICO Y ANTECEDENTES DE ESTUDIO}

La percepción social que tienen las personas del lugar en el que residen y de los fenómenos que atraviesan en su vida diaria constituye un aspecto central que colabora en el conocimiento de las necesidades de los habitantes del espacio urbano, información útil en la planificación y gestión del territorio. En el presente estudio, estas cuestiones son abordadas desde la perspectiva teórica de la Geografía de la Percepción.

Este enfoque considera los significados que las personas construyen a partir de diversos factores como, por ejemplo, el lugar de residencia, las experiencias vividas y los vínculos con el lugar como centros de significados, entre otros aspectos. Con respecto al surgimiento de esta perspectiva es importante mencionar que, a mediados de los años cincuenta, comienzan a aparecer trabajos y nuevas líneas de investigación -principalmente en el ámbito anglosajón- que centraron su atención en el comportamiento espacial y en la percepción bajo el supuesto de que el conocimiento no existe independientemente del hombre sino a partir de la experiencia humana del mundo (Gómez Mendoza, Muñoz Gimenez y Ortega Cantero, 1982).

La profundización de esta línea de investigación en el comportamiento de las personas ante el espacio permitió reorientar el trabajo de los geógrafos realizado hasta el momento desde una visión netamente neopositivista hacia una concepción más humanística (Lindon y Hiernaux, 2006). De este modo, la percepción del espacio pasó a ocupar un lugar esencial en los estudios geográficos, principalmente en el ámbito del ordenamiento territorial urbano.

Teniendo en cuenta estos aspectos es importante señalar que, en la década de 1960, comienza a surgir un conjunto de enfoques conceptuales y metodológicos que se interesaron por las actitudes, las apreciaciones y las experiencias del hombre en el proceso de conocimiento de la realidad. Algunos autores empiezan a hablar de una revolución en el comportamiento y, con la expresión de diversos postulados de la teoría behaviorista, se esbozan los primeros lineamientos teórico-metodológicos de la Geografía de la Percepción (Lindon y Hiernaux, 2006). Otros autores, definen esta corriente como una nueva línea de investigación que se interiori- za en la dimensión subjetiva a través de tendencias influenciadas por la Psicología y la Psicología Social, mediante la coexistencia de dos concepciones metodológicas distintas: una proveniente del análisis económico regional -en el ámbito demográfico- bajo las posturas de Herbert Simon en 1957 y la otra, proveniente de la Escuela de Chicago -en el ámbito urbano- encabezada por Kevin Lynch (Gómez Mendoza et al., 1982).

Según Gould y White (1974, en Gómez Mendoza et al., 1982) es tradicional en las investigaciones geográficas considerar que la mente humana genera imágenes subjetivas del medio, que terminan teniendo gran importancia en el comportamiento espacial de los individuos. No obstante estas cuestiones, existen dificultades metodológicas vinculadas con la complejidad de estudiar la subjetividad espacial ya que difiere según cada persona en función de los factores mencionados anteriormente y del contexto particular de cada comunidad. Pese a esto, el estudio de la percepción social y de la importancia que adquiere en la formación de las imágenes del mundo real de las personas, radica en comprender las decisiones espaciales que toman en función de sus motivaciones y modos de interacción social.

Con respecto a las investigaciones realizadas previamente en relación con el tema abordado, es importante destacar la contribución de Moreno Jiménez y Fuenzalida Díaz (2017) quienes utilizaron diferentes técnicas para medir el impacto socialmente percibido ante industrias contaminantes con un estimador de densidad núcleo (kernel) y SIG en el complejo industrial Ventanas, localizado en Chile. Los autores adoptaron una aproximación innovadora al combinar diferentes perspectivas teóricas y metodológicas, mediante la utilización del paradigma geotecnológico y la Geografía de la Percepción. El propósito se centraba en conocer los elementos significativos que la población percibía con respecto a los procesos de deterioro ambiental, información valiosa para la planificación y monitoreo territorial.

En relación con la combinación de técnicas para el abordaje de fenómenos socio-espaciales, Gaitán Moya y Lozano Ascencio (2013) implementaron una estrategia de triangulación de datos, de observadores, teórica y metodológica, para obtener un conocimiento más amplio de las representaciones sociales del cambio climático en el discurso de los medios de comunicación y de los jóvenes. En este sentido, la estrategia de triangulación múltiple permite abordar un fenómeno complejo desde diversos puntos de vista y, obtener así, una mayor validación del objeto de estudio abordado. 
Con respecto a la utilización de geotecnologías para abordar la percepción social que las personas construyen ante diferentes problemas, fenómenos y situaciones, es importante mencionar la contribución de Goodchild (2007), quien utiliza técnicas de análisis espacial con SIG para analizar patrones espaciales de la población de Seúl (concentración geográfica y presencia de altas densidades), a través de aplicaciones para teléfonos inteligentes con servicios basados en la ubicación (LBSN). De este modo, se consideraron las coordenadas de los lugares para analizar sus propiedades de distribución espacial dentro de una ciudad y crear un "mapa de calor" en el SIG. Uno de los aportes de esta investigación es que la información estadística se obtiene en tiempo real -a partir de las actividades desarrolladas por las personas influenciadas por sus gustos personales-, se correlaciona con datos provenientes del censo (precios de la tierra, población en edad activa) y se puede compilar rápidamente para la administración y monitoreo de la ciudad. Otra de las investigaciones que considera el análisis de la percepción social a través del uso de geotecnologías es la llevada a cabo por Brown y Reed (2012) quienes, a través de la técnica de métricas del paisaje, cuantifican las percepciones de la sociedad mediante el uso de los Sistemas de Información Geográfica de Participación Pública (SIGPP). En esta línea, también es importante destacar la contribución de Alessa, Kliskey y Brown (2008), quienes mapean Sistemas Socio Ecológicos (SES) vinculando la técnica de la encuesta y los SIG con el propósito de brindar representaciones espaciales de la interrelación entre los sistemas sociales y ecológicos. De este modo, se utiliza la información recopilada en las encuestas para valorar la percepción social que distintas comunidades de Alaska construyen del paisaje. A su vez, se incluyeron variables del medio físico para realizar cartografía de densidad, con el propósito de superponer los datos y desarrollar un análisis espacial exploratorio.

Por su parte, Palacio Buendía (2017) valoró la percepción social del potencial del paisaje y del uso público de parques naturales a través de la aplicación de encuestas digitales que incluyeron preguntas de tipo espacial para su posterior análisis en un Sistema de Información Geográfica de Participación Pública (SIGPP). De este modo, es posible conocer la información que tienen los habitantes del paisaje y su apreciación en cuanto a la calidad percibida de equipamiento e infraestructura, herramienta que posibilita crear y difundir información geográfica como soporte en la toma de decisiones.
En este contexto, también se reconoce la importancia de considerar otras fuentes de información como, por ejemplo, la que proveen las redes sociales (Facebook, Twitter, Instagram, entre otras) y sitios Web de la prensa digital. La expresión de opiniones y experiencias de los usuarios, permiten -de modo inmediato- dar a conocer hechos y sensaciones que consideran relevantes comunicar. En este sentido, según Assef (2013), los primeros trabajos que emplearon como fuente de datos la información emitida por las personas en las redes sociales, se desarrollaron en el año 2000 mediante la aplicación de la técnica de minería de datos con el propósito de analizar grandes volúmenes de información en forma automática. Estas investigaciones, tienen como objetivo reconocer patrones repetitivos, tendencias o reglas que expliquen el comportamiento de los datos en un determinado contexto.

El presente trabajo, se orienta a conocer y valorar la percepción social que un sector de los habitantes de la ciudad de Bahía Blanca tiene del arroyo Napostá Grande y su espacio fluvial, base sustancial para las decisiones de manejo y conservación del sector y para la elaboración de políticas orientadas a considerar los problemas que la comunidad local considera relevantes. Para ello, se recurre al empleo de un sistema de respuesta de voz interactiva (Interactive Voice Response) que consiste en una tecnología de telefonía que posibilita lograr una comunicación entre un usuario y un sistema automático. En la interacción, el sistema brinda diferentes opciones -a través de menús de voz configuradas previamente- para que los usuarios introduzcan sus respuestas a través de un teclado de marcación telefónico. De este modo, las respuestas obtenidas se analizan en función de los conceptos, categorías y dimensiones de análisis propuestas por la Geografía de la Percepción y se espacializan a través de la elaboración de cartografía temática con el propósito de analizar las percepciones espaciales y establecer propuestas de gestión del territorio según la localización de los encuestados.

\section{ÁREA DE ESTUdio, FUENTES Y METOdologíA}

\section{Localización del área de estudio}

El ámbito seleccionado se sitúa en el tramo inferior del arroyo Napostá Grande, curso fluvial que se origina en el cordón de Ventana y que, luego de recorrer $108 \mathrm{~km}$ desemboca en el estuario de la bahía Blanca (Carrica, 1998). El cauce natural del arroyo atraviesa la ciudad de Bahía Blanca ( $38^{\circ} 44^{\prime}$ latitud Sur y $62^{\circ} 16^{\prime}$ 
longitud Oeste) que es cabecera del partido homónimo y cuenta con 301.572 habitantes (INDEC, 2010).

La localidad se encuentra atravesada por el arroyo Napostá Grande en dirección Norte-Sur y, en su paso a través del espacio urbano, ha sido modificado por distintas obras de ingeniería destinadas a mitigar el efecto de las crecidas que llegaron a anegar vastos sectores. En el área urbana, una parte del arroyo continúa su cauce natural (entubado en el tramo de calle Casanova hasta la calle Estados Unidos) y otra parte se deriva al canal Maldonado que constituye un aliviadero frente a las posibles crecidas del curso (figura 1). Esta obra, si bien ha contribuido a alivianar los eventos de exceso de precipitaciones, frente a períodos de intensas lluvias, no es suficiente para evacuar la totalidad del caudal, lo que determina que ciertas áreas de la ciudad se encuentren afectadas ante un riesgo de inundación.
Se destaca la presencia de diversos usos del suelo, con el predominio del recreativo, debido a la existencia de diferentes espacios verdes, tales como el Parque de Mayo, el Paseo de las Esculturas y el Paseo Lineal Ribera del Napostá. Según Santamaría y Aldalur (2014), el sector configura una zona sujeta a futuro ordenamiento del suelo emplazada en un valle de inundación del arroyo, donde actualmente existe un gran porcentaje de parcelas cuyo uso del suelo es recreativo -deportivo-, residencial -por la presencia de quintas de viviendas- y comercial.

Por su parte, es importante mencionar que el área abordada se encuentra totalmente urbanizada con el predominio de barrios privados y quintas en el sector norte, espacios verdes y viviendas unifamiliares en su mayor parte del recorrido y asentamientos precarios en el sector de su desembocadura. Esta situación ex-

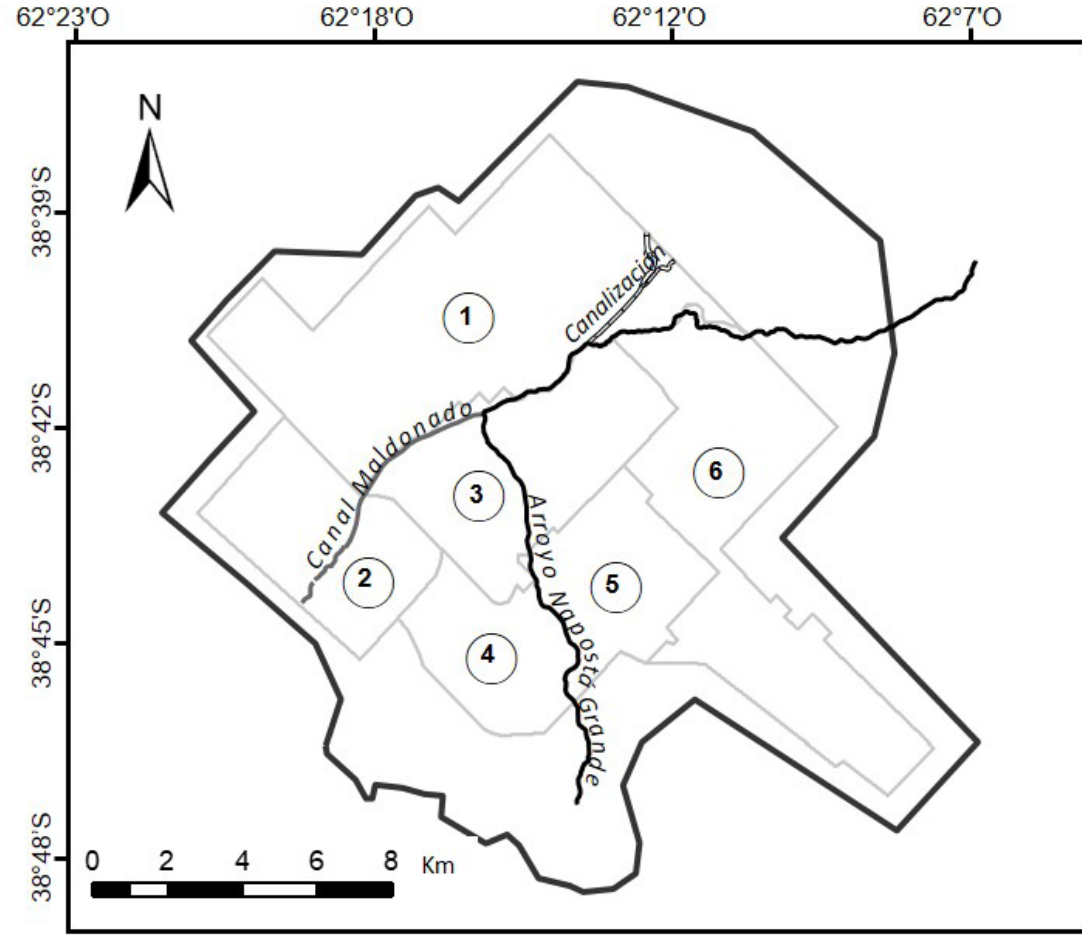

Referencias

1 Delegación Norte

2 Delegación Noroeste

3_Delegación Centro
4 Delegación Villa Rosas
5 - Delegación Las Villas
6_Delegación Harding Green
Área de estudio: casco urbano

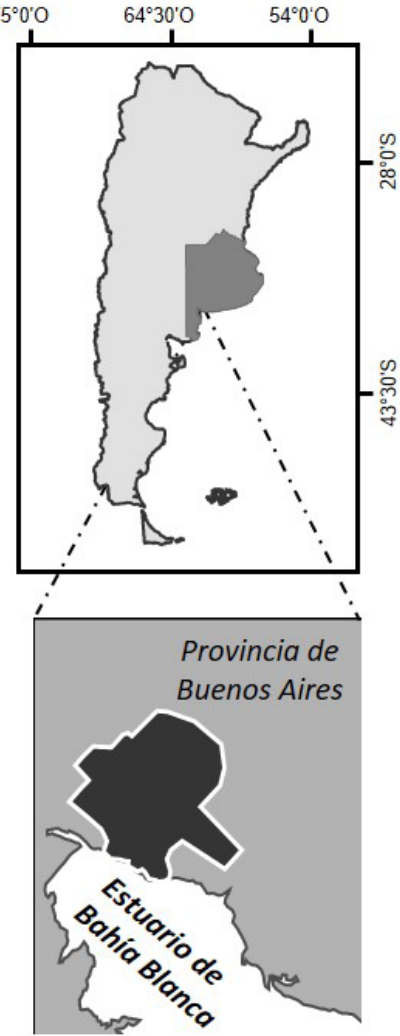

Fuente: elaboración propia. 
pone a los residentes de este último espacio a diferentes problemas relacionados principalmente con el inadecuado mantenimiento y limpieza del arroyo como de su espacio fluvial, y a consecuencias derivadas de esta situación como, por ejemplo, la presencia de residuos y problemas sanitarios y ambientales.

En este sentido, Prieto (2013) sostiene que:

"[...] las condiciones se tornan más deficitarias a medida que aumenta la distancia a las áreas centrales, con los casos más críticos localizados en la periferia donde se encuentran los asentamientos carenciados. Es allí donde se registran las condiciones más graves de pobreza, los grupos sociales más vulnerables, que por carecer de recursos resuelven sus problemas habitacionales en viviendas precarias, con inadecuada dotación de servicios básicos, en un hábitat ambientalmente degradado y con dificultades en la accesibilidad y la integración a la ciudad consolidada" (Prieto, 2013:69).

Teniendo en cuenta la degradación ambiental del sector sur, suroeste y sureste de la ciudad de Bahía Blanca es importante destacar la importancia que reviste la percepción social de la población con respecto al estado del arroyo y a los principales problemas que atraviesan para la elaboración de un diagnóstico que incluya sus necesidades en la planificación y gestión territorial. Así, por ejemplo, se hace evidente la necesidad de incorporar nuevos espacios verdes recreativos y generar las condiciones para la limpieza y mantenimiento del arroyo, especialmente en su tramo final, con el propósito de brindar una mejor calidad de vida a los residentes de estos sectores.

\section{Fuentes de información}

Se recurre a la aplicación de técnicas cuantitativas como las TIC's y TIG's, cuya utilización contribuye a evitar los sesgos metodológicos derivados del uso de un único enfoque, aspecto que permite obtener una mayor validación de los resultados (Dobson, 1993; Denzin, 2009). En este sentido, se combinan técnicas cuantitativas, herramientas que posibilitan conocer y espacializar la percepción que un sector de la población de la ciudad tiene respecto del estado de conservación del arroyo Napostá Grande y de su espacio fluvial con el propósito de integrar información múltiple y diversa en un SIG.

Así, en el proceso metodológico, se diseña un cuestionario realizado según las consideraciones teóricas propuestas por García Ballesteros y Bosque Sendra (1989). Es importante mencionar que, el cuestionario inicial, fue confeccionado en el marco de una investigación mayor, por lo cual, fue necesa- rio utilizarlo como modelo y adaptarlo a través de una selección y ajuste de las preguntas más representativas relacionadas con el objetivo del presente estudio. El cuestionario (ver anexo) incluye preguntas vinculadas con la percepción social del arroyo, su estado, como así también aspectos relacionados con los principales problemas que se manifiestan en el espacio fluvial. Para efectuarlo, se utilizó un sistema de llamadas automático de plataforma IVR (Interactive Voice Response) que permite recopilar un gran volumen de información en corto período de tiempo a través de llamados telefónicos. Con respecto a la aplicación de esta técnica, es importante mencionar que, el sistema sistematizado de respuestas de voz interactiva, es una valiosa herramienta que brinda en el corto plazo una gran cantidad de datos con un reducido margen de error. Asimismo, supera los inconvenientes que presentan otro tipo de encuestas ya que se puede gestionar de una manera más eficaz el tiempo en el que se realiza la encuesta y el momento en el que se recibe la información.

La selección de los encuestados se realiza a partir de un muestreo probabilístico, sistemático, considerando a la población total como universo. Según Vieytes (2004), un muestreo es probabilístico cuando cualquier elemento de una población o universo posee una probabilidad conocida y, distinta de cero, de pertenecer a la muestra. Dentro de este tipo de muestreo se utiliza el denominado "al azar sistemático" que exige un procedimiento de numeración de todos los elementos de la población -procedimiento automático que se efectúa a través de un sistema de cómputo- para extraer unidades a través de una serie de operaciones numéricas. En este estudio, la muestra final (2047) reúne a personas de diferentes edades distribuidas aleatoriamente en la totalidad de las delegaciones de la ciudad. Cabe destacar que, la muestra considerada, arroja un margen de error de +/-3 con un intervalo de confianza del $95 \%$ y que la totalidad de las respuestas varían en función de cada interrogante debido a que no todas las personas encuestadas respondieron la misma cantidad de preguntas.

\section{Técnicas de análisis}

La realización de cuestionarios en las delegaciones de la ciudad de Bahía Blanca consideradas en el estudio -distribuidos aleatoriamente mediante la técnica IVR- permite asumir una importante representatividad de la muestra seleccionada y de las respuestas obtenidas. De acuerdo con el propósito de la inves- 
tigación, las respuestas consideradas para el análisis han sido aquellas afirmativas que aluden específicamente al estado del arroyo Napostá Grande (muy bueno, bueno y regular y malo); a los problemas percibidos en el espacio fluvial (vertidos domiciliarios e industriales e inadecuado mantenimiento/limpieza y problemas sanitarios) y a la percepción del arroyo $\mathrm{Na}$ postá Grande (como espacio deteriorado).

La información recopilada se espacializa, a través de la georreferenciación de los datos en función del domicilio de los encuestados y se representa mediante la realización de cartografía temática a partir del empleo de un estimador de densidad focal núcelo (kernel) bajo el modelo raster. Su aplicación, posibilita asumir que un dato puntual se despliega por un entorno alrededor de cada domicilio, representando, de este modo, la cantidad de respuestas en una primera etapa, para luego, espacializar la densidad de ellas. Siguiendo a Moreno Jiménez y Fuenzalida Díaz (2017), se trataría de una especie de "entorno personal próximo" (EPP) en el que la persona desarrolla actividades cotidianas varias, centradas y factibles desde el punto-domicilio. A los efectos del presente estudio se fijó ese parámetro en 250 metros, radio de búsqueda de las respuestas afirmativas, mientras que el tamaño de la celda que ha sido fijado es de 50 metros.

Con respecto a la técnica de densidad, la concentración de respuestas -donde pesan más los píxeles cercanos y menos los distantes- posibilita una representación visual de las densidades ni demasiado suavizadas ni demasiado detalladas a través del método de rupturas naturales o "Jenks", en 5 clases. Las capas de densidad se representan, por un lado, a través de dicho método $y$, por el otro, reclasificadas en intervalos de igualdad con el propósito de hacer comparables los mapas realizados y plantear categorías de densidad de respuestas (muy baja, baja, media, alta y muy alta). Esta última representación se ha realizado debido a que la amplitud de las densidades de cada capa difiere en función de la cantidad de respuestas afirmativas a cada pregunta y, para evitar esta inconsistencia entre capas, se adoptó una amplitud constante.

De este modo, en las capas raster derivadas de cada pregunta del cuestionario, se observarán píxeles con mayor densidad, dado que se concentran de un modo marcado las respuestas afirmativas que han sido respondidas y con menor densidad donde hay un menor número de ellas. El resultado expresaría, de este modo, una representación cuantitati- va de la percepción social que los habitantes de la ciudad de Bahía Blanca elaboran acerca del estado del arroyo Napostá Grande y su espacio circundante y de los principales problemas relacionados con el curso fluvial. En la investigación, el tratamiento ha sido realizado con el software $\operatorname{ArcGIS}{ }^{\circledR}$, en el que se encuentra disponible la función cuadrática de densidad de probabilidad núcleo (kernel). Según Silverman (1986), la técnica permite ponderar los puntos, que están en el interior de un círculo, en forma desigual y de acuerdo con la distancia que estos tienen respecto al centroide. Así, los puntos más cercanos al centroide, tendrán más peso que los más alejados. Genéricamente el estimador puede escribirse así:

Densidad Kernel $\left(L_{j}\right)=\Sigma 3 / \Pi \cdot r^{2} *\left(1-d^{2}{ }_{i j} / r^{2}\right)^{2}$

Donde:

$D_{i j}$ es la distancia entre el punto i y j

r es el radio del círculo establecido

$\mathrm{C}_{\mathrm{j}}$ es el conjunto formado por los i puntos cuya distancia al centroide del pixel j es menor que $r$.

\section{RESULTADOS}

Del análisis de las respuestas obtenidas (2047) se identifica el conjunto del ámbito de estudio y luego, por delegación, la percepción social que las personas construyen con respecto al curso fluvial, a su estado de conservación y a los principales problemas (figura 2). Con respecto a las delegaciones de la ciudad de Bahía Blanca, es importante mencionar que, las mismas, constituyen la unidad básica de gestión municipal por lo que es fundamental realizar aportes que las incluyan como base de un análisis geoespacial. En el presente estudio, las delegaciones tenidas en cuenta son: Centro, Norte, Noroeste, Las Villas, Villa Rosas y Harding Green. Si bien en la ciudad de Bahía Blanca existen en total ocho delegaciones, a los efectos de la presente investigación, se seleccionaron las mencionadas anteriormente debido a que son las que presentan una mayor proximidad con el arroyo y su espacio fluvial.

Por otro lado, es importante destacar que la cantidad total de respuestas para cada interrogante fluctúa de acuerdo con la frecuencia con la que los encuestados hayan respondido la totalidad del cuestionario. Por este motivo, el análisis y representación espacial de las respuestas, se realiza de modo individual teniendo en cuenta los datos expresados en la tabla I. 
FIGURA 2

DISTRIBUCIÓN DE LAS RESPUESTAS OBTENIDAS EN EL CUESTIONARIO

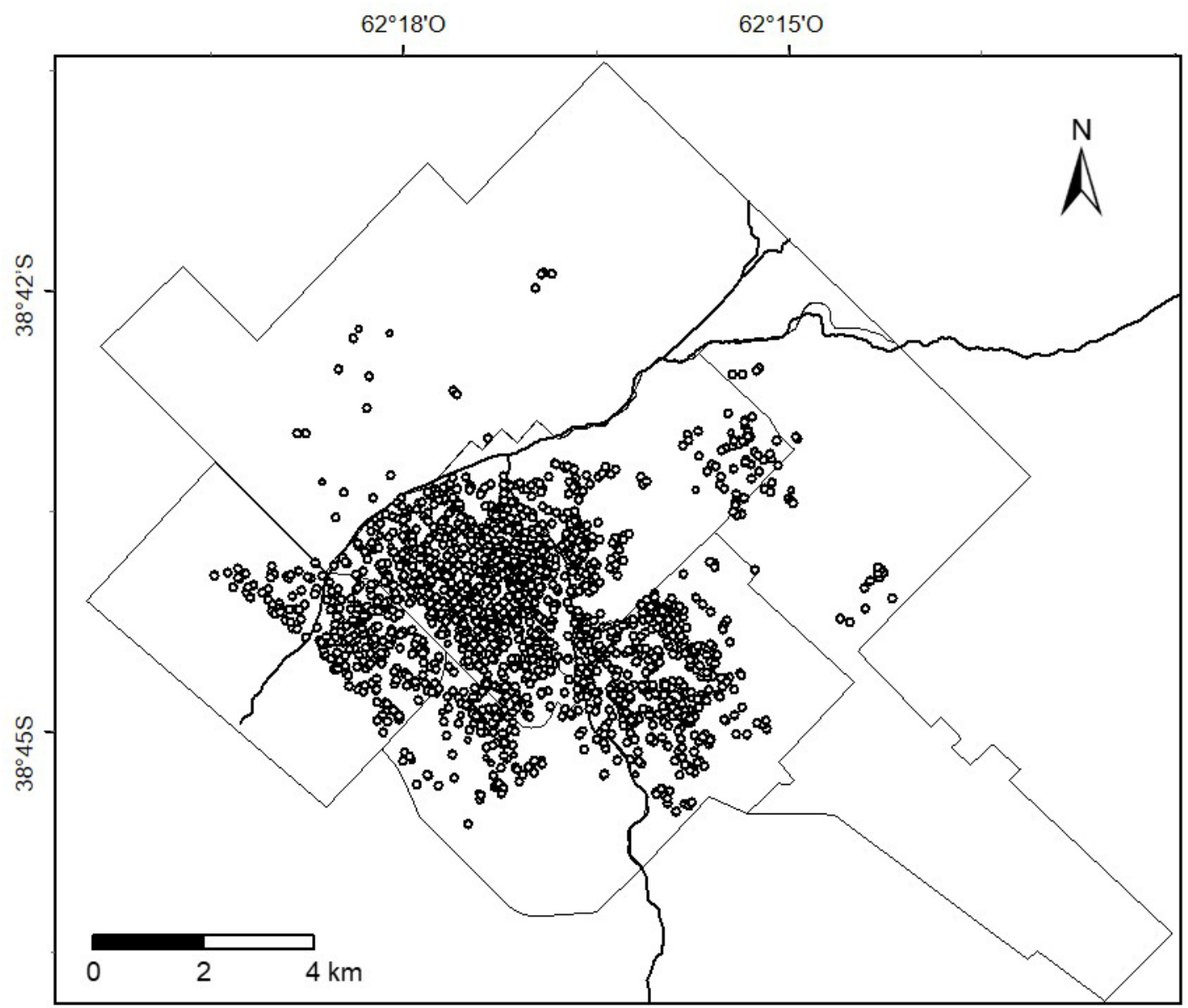

Fuente: elaboración propia sobre la base de los cuestionarios efectuados.

TABLA 1

CANTIDAD TOTAL DE RESPUESTAS DE LA PERCEPCIÓN SOCIAL DE ENCUESTADOS SEGÚN INTERROGANTE

\begin{tabular}{|c|c|c|c|c|c|c|c|c|}
\hline \multicolumn{4}{|c|}{$\begin{array}{c}\text { Estado del arroyo Napostá Grande } \\
\text { y su espacio fluvial }\end{array}$} & \multicolumn{2}{|c|}{$\begin{array}{c}\text { Problema: } \\
\text { vertidos } \\
\text { domiciliarios (D) e } \\
\text { industriales (I) }\end{array}$} & \multicolumn{2}{|c|}{$\begin{array}{c}\text { Problema: inadecuado } \\
\text { mantenimiento (M) y limpieza (L) }\end{array}$} & $\begin{array}{c}\text { Espacio } \\
\text { degradado }\end{array}$ \\
\hline \multicolumn{4}{|c|}{1711} & \multicolumn{2}{|c|}{429} & \multicolumn{2}{|c|}{1178} & \multirow{5}{*}{714} \\
\hline & & & & D & I & M y L & $\begin{array}{l}\text { Problemas } \\
\text { sanitarios }\end{array}$ & \\
\hline \multicolumn{2}{|c|}{576} & \multicolumn{2}{|c|}{1135} & \multirow{3}{*}{135} & \multirow{3}{*}{294} & \multirow{3}{*}{1039} & \multirow{3}{*}{139} & \\
\hline $\mathrm{MB}$ & B & $R$ & $\mathrm{M}$ & & & & & \\
\hline 117 & 459 & 830 & 305 & & & & & \\
\hline
\end{tabular}

En la tabla, se expresan las preguntas seleccionadas del cuestionario y sus respectivas opciones de respuestas, según la cantidad de personas que respondieron cada una de ellas. Con respecto a la pregunta que alude al estado del arroyo y su espacio fluvial, las opciones fueron: Muy buen estado (MB), buen estado (B), estado regular (R) y mal estado (M). En relación con la percepción de los problemas representativos del sector, se ha seleccionado del cuestionario la opción: presencia de vertidos domiciliarios (D) y de vertidos industriales (I). Finalmente, se ha tenido en cuenta la percepción del arroyo y su espacio fluvial como espacio degradado.

Fuente: elaboración propia sobre la base de los cuestionarios efectuados. 
Teniendo en cuenta la cantidad total de encuestados es posible analizar que, con respecto a la percepción social del estado del arroyo y de su espacio circundante, el $37,66 \%$ del total de la población encuestada considera que el estado es regular, el $22,2 \%$ no sabe, el $21,02 \%$ expresa que es bueno, el $13,83 \%$ percibe que es malo y finalmente, el 5,29\% considera que es muy bueno (figura 3). En este sentido, la percepción social que la población consultada tiene del estado del arroyo Napostá Grande y de su espacio fluvial, se relaciona en mayor medida con la situación de abandono del cauce, motivos por los cuales expresan que su estado es regular y en el otro extremo, un mínimo porcentaje considera que es muy bueno. No obstante, existe una proporción importante de población que no tiene conocimiento, razón por la cual es relevante considerar la ausencia de este elemento en la imagen mental construida del espacio urbano.

FIGURA 3

PERCEPCIÓN DEL ESTADO DEL ARROYO NAPOSTÁ GRANDE

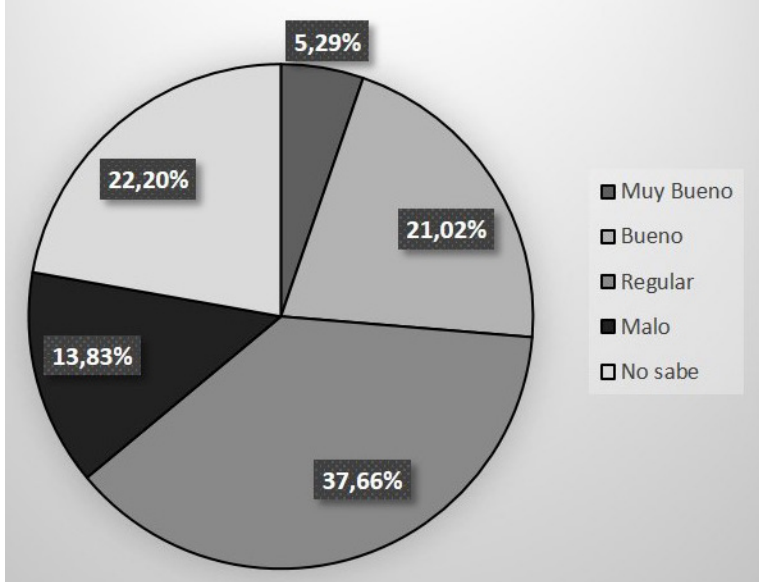

Fuente: elaboración propia sobre la base de los cuestionarios efectuados.

Teniendo en cuenta el mismo interrogante, pero diferenciando las repuestas según las delegaciones de la ciudad de Bahía Blanca, es posible observar que las delegaciones Norte, Centro, Noroeste y Las Villas, consideran que, en mayor medida, el estado es regular. Por el contrario, los habitantes de las delegaciones Villa Rosas y Harding Green no tienen conocimiento o no saben cuál es el estado del arroyo. Estas diferencias ponen de manifiesto que la distancia con respecto al curso fluvial y a su espacio circundante es un factor clave en la percepción y conocimiento que los residentes de dichos sectores tienen del mismo, debido a que son las dos delegaciones que se encuentran más alejadas del área bajo estudio. Otro aspecto a destacar con respecto a las delegaciones que consideran en mayor proporción que el estado es regular (Norte, Centro, Noroeste y Las Villas), es que en segundo lugar sostienen que el arroyo se mantiene en buen estado (figura 4), cuestión que representa una dualidad que debe considerarse en el análisis de la percepción social que los habitantes construyen.

Las diferencias establecidas entre los habitantes manifiestan diversas percepciones con respecto al arroyo y a su área circundante. Es importante destacar que el arroyo no presenta las mismas características a lo largo de todo su recorrido, motivo por el cual puede explicarse la percepción diferencial según delegación y barrio de residencia. Así, por ejemplo, en los barrios del sector sur, sureste y suroeste de la ciudad se intensifican las situaciones de deterioro de la calidad de vida en lo que respecta a condiciones habitacionales, sanitarias, nivel de instrucción y provisión de servicios básicos, factores que contribuyen a un deterioro de la calidad ambiental (Prieto, 2013). Por su parte, en ciertos sectores de la delegación centro y, especialmente en la delegación norte, existen áreas dedicadas a un uso del suelo recreativo (en el sector del valle de inundación del arroyo) con la intervención en diversas obras como la parquización e incorporación de espacios deportivos, factores que promueven una apropiación del espacio por parte de la comunidad local para el desarrollo de distintas actividades de esparcimiento.

Como afirma Santos (1990), cada individuo al tener una forma concreta de conocer el espacio presenta diferentes representaciones de los objetos que lo conforman y en el proceso de conocimiento existe una percepción diferencial de la realidad que es diversa, a veces parcial y deformada. Así, la existencia de diversas imágenes mentales que las personas construyen del espacio no sólo constituye una forma de comprenderlo, sino que también, se asocia con aquellas emociones y sentimientos vinculados al espacio vivido, de allí la importancia que representa para cada sujeto.

En este sentido es fundamental analizar las razones que explican las percepciones diferenciales de ciertos elementos, hechos y procesos en detrimento de otros debido a que los sistemas perceptivos se encuentran articulados a una serie de procesos mentales que filtran la información que se recibe del medio. Por este motivo, algunos grupos perciben las amenazas a las que se exponen, ciertos elementos del medio y determinados problemas y otros grupos no lo hacen o no tienen conocimiento de ellos de acuerdo a una serie de factores. Entre ellos se pueden mencionar: el lugar de residencia (barrio, delegación), la información recibida y las experiencias vividas, entre otros aspectos. 

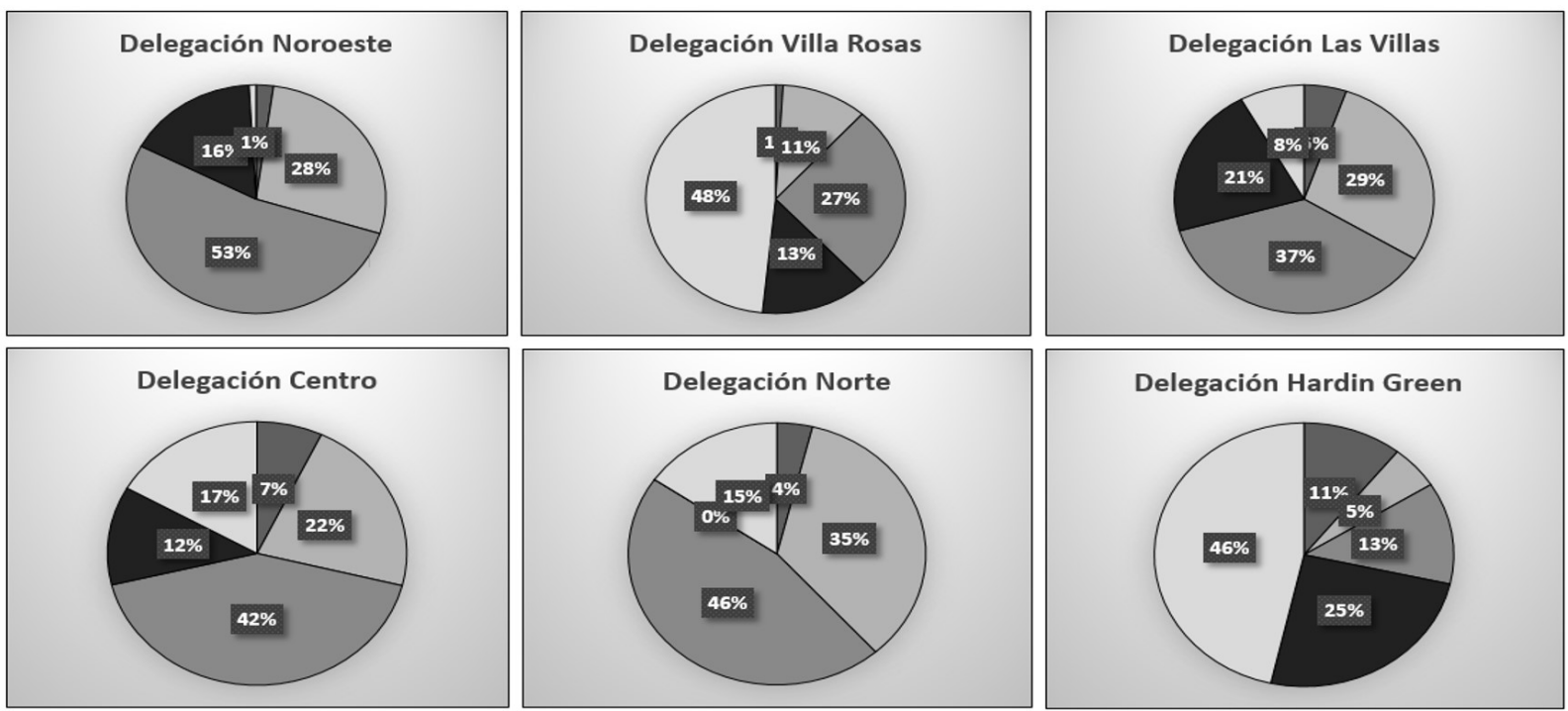

\begin{tabular}{|l|r|r|r|r|r|}
\hline \multicolumn{6}{|c|}{ Percepción del estado de deterioro del área de estudio (en \%) } \\
\hline \multicolumn{1}{|c|}{ Delegación } & Muy Bueno & \multicolumn{1}{|c|}{ Bueno } & \multicolumn{1}{c|}{ Regular } & \multicolumn{1}{c|}{ Malo } & NS/NC \\
\hline Noroeste & 2,16 & 27,71 & 52,81 & 16,45 & 0,87 \\
\hline Villa Rosas & 0,93 & 10,70 & 26,51 & 13,49 & 48,37 \\
\hline Las Villas & 5,29 & 28,46 & 36,78 & 21,41 & 8,06 \\
\hline Centro & 7,08 & 21,85 & 42,23 & 12,09 & 16,75 \\
\hline Norte & 3,85 & 34,62 & 46,15 & 0,00 & 15,39 \\
\hline Harding Green & 10,71 & 5,36 & 12,50 & 25,00 & 46,43 \\
\hline
\end{tabular}

$\square$ Muy Bueno
$\square$ Bueno
$\square$ Regular
$\square$ Malo
$\square$ Ns/Nc

Fuente: elaboración propia sobre la base de los cuestionarios realizados.

En relación con la percepción que tiene la población encuestada del principal problema relacionado con el estado del cauce del arroyo, una proporción significativa del total de la población encuestada considera que la falta de limpieza y mantenimiento inadecuado es el principal conflicto (50\%). Por su parte, un $25 \%$ no sabe, un $12 \%$ expresa que el principal conflicto se debe a la presencia de vertidos industriales, un $7 \%$ a problemas sanitarios $y$, finalmente, un $6 \%$ a vertidos domiciliarios. De este modo, el principal inconveniente percibido por la mitad los vecinos encuestados -con respecto al arroyo y a su espacio circundante- se vincula con la ausencia de mantenimiento y limpieza en el sector, aspecto que puede generar sensaciones de rechazo con respecto al espacio fluvial (figura 5). En este contexto, es dable mencionar que se han realizado tareas de saneamiento por parte del municipio local, aunque de forma aislada, especialmente luego de períodos de intensas precipitaciones. La generación de desbordes del arroyo por la acumulación de residuos domiciliarios e industriales, crecimiento de vegetación y arrastre de sedimentos desde la cuenca superior y media del arroyo han sido fenómenos recurrentes. Sin embargo, las acciones de monitoreo, mantenimiento y saneamiento del cauce y del recurso hídrico en general, no se realizan de forma periódica, aspectos que inciden en la percepción que los habitantes construyen del arroyo y su espacio fluvial.

FIGURA 5

PROBLEMAS RELACIONADOS CON EL ESTADO DEL CAUCE DEL ARROYO NAPOSTÁ GRANDE

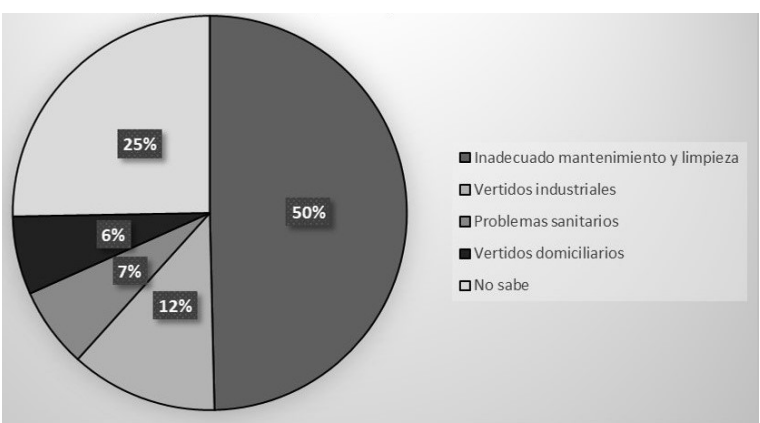

Fuente: elaboración propia sobre la base de los cuestionarios realizados.

Por su parte, teniendo en cuenta las respuestas obtenidas por delegación es posible identificar que todas las delegaciones -exceptuando Villa Rosas- consideran que el principal conflicto se relaciona con el inadecuado mantenimiento y limpieza del sector. En 
el caso de Villa Rosas predomina el desconocimiento con respecto a dicho interrogante, aspecto que puede interpretarse como una ausencia del arroyo y de su espacio fluvial en la imagen mental construida por los residentes de dichos sectores (figura 6). Sin embargo, como segunda opción consideran que el inadecuado mantenimiento y limpieza es el principal problema.

Al observar la cartografía con la espacialización de las respuestas obtenidas, es posible identificar que en las delegaciones Norte, Centro, Noroeste y Las Villas se concentran de un modo muy marcado las respuestas que aluden al inadecuado mantenimiento y limpieza como el principal problema del espacio fluvial local. Esta circunstancia se relaciona con el grado de proximidad al sector y con las vivencias y experiencias cotidianas de los habitantes de dichas delegaciones con respecto a las características del paisaje que observan en sus recorridos diarios.

Con respecto a la pregunta realizada anteriormente, es posible establecer una conexión con el interro- gante que hace alusión a la percepción del arroyo y a su espacio circundante. En este sentido, en primer lugar, el $35,4 \%$ del total de la población encuestada considera que es un espacio degradado. Sin embargo, en segundo lugar, el $20,4 \%$ de los vecinos consultados cree que el arroyo representa un elemento significativo de la localidad; en tercer lugar, el $18,7 \%$ no sabe, en cuarto lugar, el $18,3 \%$ lo considera un espacio de recreación y finalmente en quinto lugar, el 7,1\% como un lugar de paso (figura 7).

Estas contradicciones manifiestan las percepciones diferenciales con respecto al arroyo y a su espacio fluvial ya que si bien presenta condiciones que le atribuyen un estado degradado y deteriorado, al mismo tiempo constituye un elemento representativo para la ciudad y para sus habitantes. De esta manera, si bien existen diversas concepciones con respecto a dicho curso, en general se observan coincidencias con respecto a los problemas relacionados con su estado.

FIGURA 6

PERCEPCIÓN DE LOS PROBLEMAS IDENTIFICADOS EN EL ARROYO NAPOSTÁ GRANDE Y SU ESPACIO FLUVIAL (EXPRESADO EN \%)

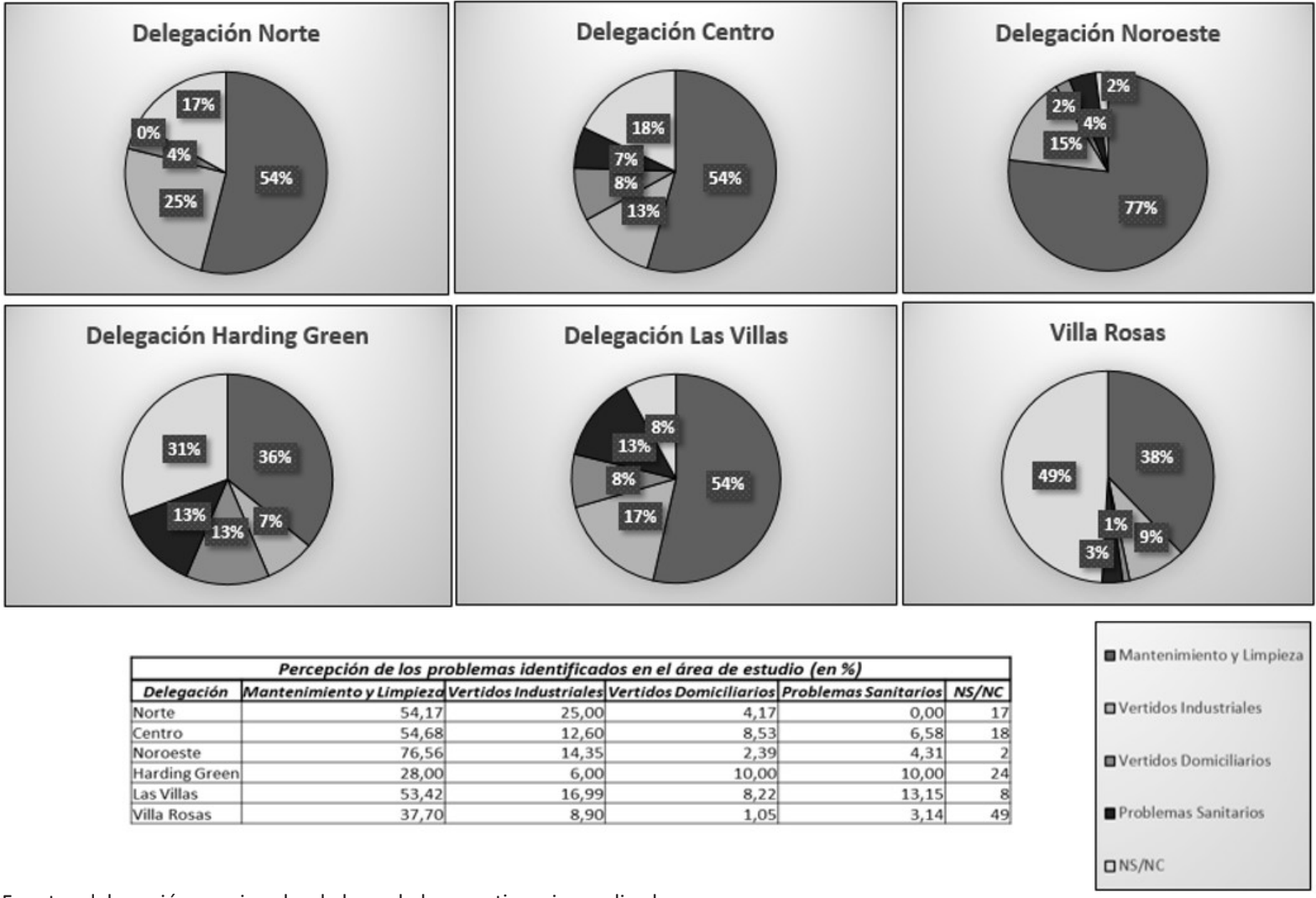

Fuente: elaboración propia sobre la base de los cuestionarios realizados. 
FIGURA 7

PERCEPCIÓN DEL ARROYO NAPOSTÁ GRANDE Y SU ESPACIO CIRCUNDANTE EN RELACIÓN CON LOS PRINCIPALES PROBLEMAS RELACIONADOS AL ESTADO DEL CAUCE

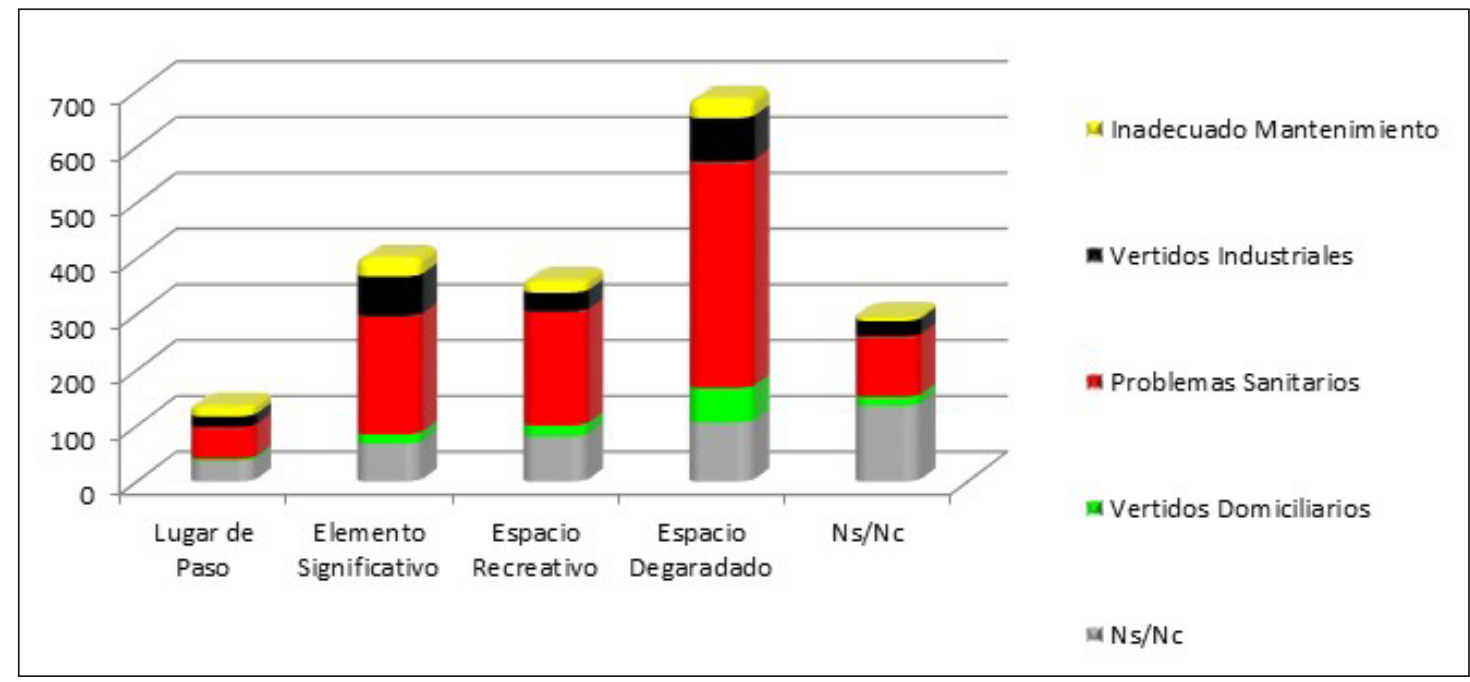

Fuente: elaboración propia sobre la base de los cuestionarios realizados.

Por su parte, al realizar un análisis por delegaciones, se observa que el desconocimiento de la percepción social del arroyo Napostá Grande predomina en las delegaciones de Villa Rosas y Harding Green. No obstante, las delegaciones Noroeste, Centro y Las Villas, consideran al arroyo y a su espacio como un lugar degradado, aspecto que puede interpretarse en la cartografía realizada a través de una densificación de las respuestas en dichas delegaciones. Esta concepción puede explicarse a partir de la proximidad espacial a dicho sector, aspecto que le otorga un significado vivido por los habitantes que lo transitan cotidianamente $y$, desconocido, por quienes se encuentran más alejados (figura 8).

Asimismo, es importante mencionar la percepción que los habitantes de la delegación Norte tienen del arroyo y de su espacio circundante, ya que lo relacionan con un espacio recreativo en primera instancia y como un elemento significativo de la ciudad en segunda instancia. Estas consideraciones conducen a interpretar que, en el sector, la presencia de espacios verdes (Parque de Mayo, Paseo de las Esculturas, Paseo Lineal de la Ribera del Napostá, entre otros) en su óptimo estado de conservación y el uso del suelo recreativo, inciden en la percepción social que los vecinos de la delegación Norte construyen del espacio fluvial.

\section{La densidad espacial de la muestra}

La distribución espacial de las respuestas obtenidas en la realización del cuestionario manifiesta un patrón de densidad que abarca la totalidad de las delegaciones analizadas (ver figura 2). La representación espacial de las opiniones con respecto al estado del arroyo Napostá Grande, de su espacio fluvial como así también de los problemas identificados en el sector, manifiesta un reparto con cierta regularidad en dichas delegaciones.

En relación con el número de respuestas obtenidas para cada interrogante es posible identificar variaciones debido a que no todas las preguntas fueron respondidas por la misma cantidad de personas. Sin embargo, el gran número de respuestas contestadas permite realizar un análisis por delegación representativo de la percepción social del estado de conservación del espacio fluvial en función de los patrones espaciales. Estos resultados varían según los factores diferenciales que inciden en la percepción social del sector, motivo por el cual, en una primera instancia, se analizan de forma separada:

\section{a) El estado del arroyo Napostá Grande}

Teniendo en cuenta los resultados obtenidos a partir de la utilización de la técnica de densidad kernel para el indicador "Estado del arroyo Napostá Grande" 
FIGURA 8

PERCEPCIÓN DEL ARROYO NAPOSTÁ GRANDE Y SU ESPACIO FLUVIAL (EXPRESADO EN \%)
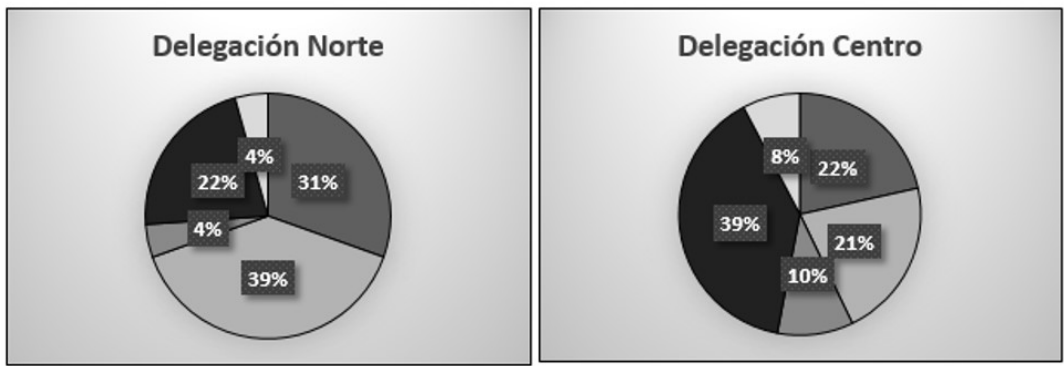

Delegación Harding Green
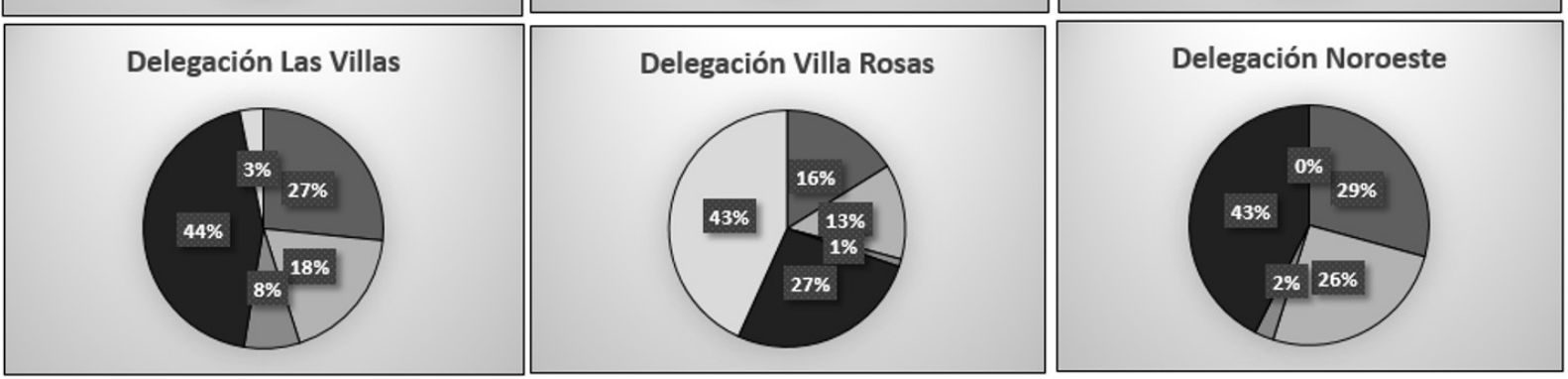

\begin{tabular}{|l|r|r|r|r|r|}
\hline \multicolumn{7}{|c|}{ Percepción del arroyo Napostá Grande y su espacio fluvial (expresado en \%) } \\
\hline Delegación & Elemento significativo & Espacio recreativo & Lugar de paso & Espacio degradado & NS/NC \\
\hline Norte & 30,43 & 39,13 & 4,35 & 21,74 & 4,35 \\
\hline Centro & 21,53 & 21,33 & 10,14 & 39,29 & 7,72 \\
\hline Harding Green & 6,25 & 4,17 & 10,42 & 35,42 & 43,75 \\
\hline Las Villas & 26,59 & 18,50 & 7,51 & 44,22 & 3,18 \\
\hline Villa Rosas & 16,15 & 13,02 & 1,04 & 26,56 & 43,23 \\
\hline Noroeste & 29,23 & 25,64 & 2,56 & 42,56 & 0,00 \\
\hline
\end{tabular}

口Elemento significativo

Espacio recreativo

口Lugar de paso

Espacio degradado

$\square \mathrm{NS} / \mathrm{NC}$

Fuente: elaboración propia sobre la base de los cuestionarios realizados.

-con 1711 respuestas- es posible observar que, la mayor cantidad de respuestas, se localizan en la delegación Centro en primer lugar, Las Villas en segundo lugar, en la delegación Noroeste en tercer lugar y, finalmente, una menor proporción en la delegación Villa Rosas. Puede inferirse que esta situación se relaciona con la cercanía del curso y del espacio fluvial a estas delegaciones y a la utilización del sector de forma más frecuente que el resto, motivo por el cual, la densificación de las respuestas se visualiza en las delegaciones antes mencionadas.

En este sentido, la percepción social del estado del arroyo y de su espacio fluvial se evidencia en las respuestas obtenidas a través de dos indicadores: el primero, corresponde a un "estado muy bueno y bueno", mientras que el segundo, a un "estado regular y malo". Estos indicadores fueron seleccionados del cuestionario realizado con el propósito de conocer la percepción que las personas de la ciudad tienen con respecto al estado general del sector. Para la representación espacial se excluyó del análisis el número de opiniones que no han contestado el cuestionario y se representó cada indicador de forma separada, con el fin de identificar la densidad de respuestas correspondientes a cada uno de ellos.

Asimismo, del total de los encuestados que respondieron que el estado del arroyo era "muy bueno y bueno" (576 casos) -buen estado- puede observarse en el mapa de densidad que, la delegación Centro reúne la mayor cantidad de respuestas con una densidad alta y, en los sectores que se encuentran próximos al arroyo, aparecen algunos casos que perciben el espacio fluvial en buen estado con una densidad alta y media (figura 9). Por ejemplo, en la delegación Las Villas, se manifiesta cierta concentración de respuestas con una densidad media y alta y en la delegación Noroeste predomina una densidad media, como en toda el área circundante al arroyo y a su espacio fluvial. Sin embargo, las respuestas que corresponden a una densidad baja se localizan en las delegaciones que se encuentran más alejadas del espacio fluvial. Estas percepciones expresan que el lugar de residencia y la proximidad con el arroyo Napostá Grande y su espacio fluvial intervienen en la concepción que los habitantes construyen de dicho sector y de sus conflictos. 
FIGURA 9

DENSIDAD NÚCLEO KERNEL DE RESPUESTAS QUE ALUDEN A LA PERCEPCIÓN DEL INDICADOR “BUEN ESTADO" DEL ARROYO NAPOSTÁ GRANDE Y SU ESPACIO FLUVIAL a)

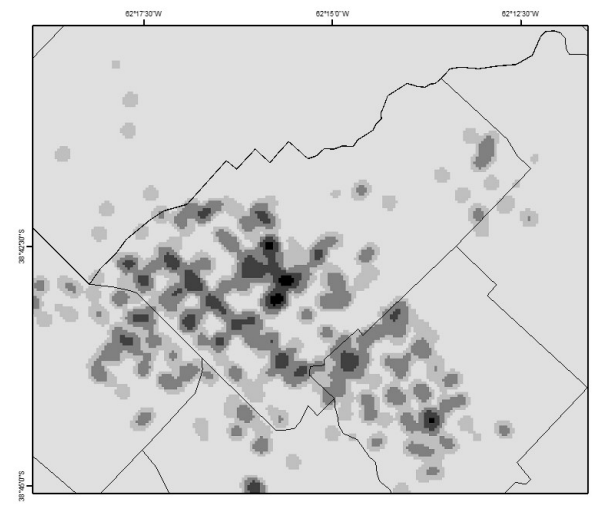

Referencias Densidad de respuestas "Buen estado" <VALUE> $\square_{0,031-0,1}^{0-0,03}$ $0,11-0,25$
$0,26-0,5$ 0,51-0,7

b)
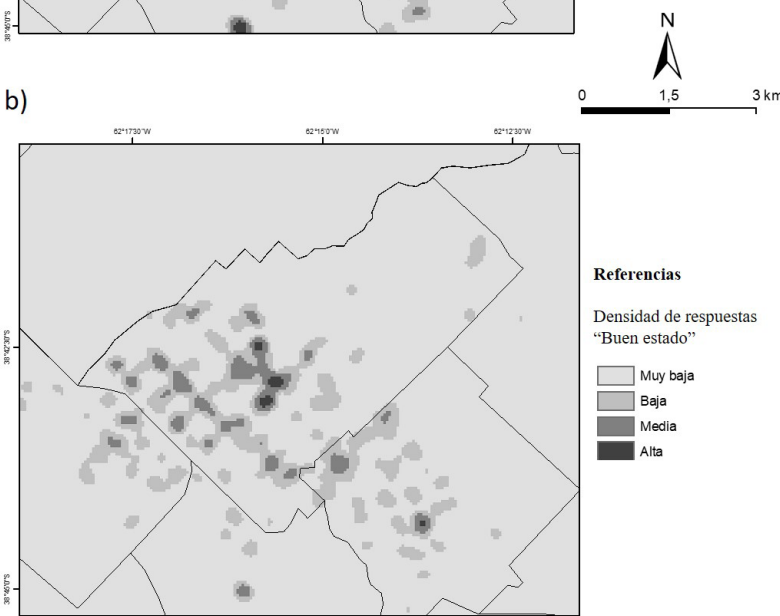

Fuente: elaboración propia sobre la base de los cuestionarios realizados.

Con respecto al indicador que se refiere a la percepción del estado del arroyo de un modo "regular y malo" (1135 casos) -mal estado-, la localización de las respuestas se evidencia en las delegaciones Centro, Las Villas y Noroeste y, en menor medida, en la delegación Villa Rosas, pero con mayor homogeneidad en la distribución de las respuestas que en el anterior caso, sin contrastes representativos. Este aspecto expresa que, con respecto a la percepción del espacio fluvial en mal estado, las respuestas se observan con mayor frecuencia y cierta regularidad lo que evidencia una concepción compartida del estado de deterioro del sector (figura 10).

De este modo, es posible reconocer que quienes perciben el arroyo y su espacio fluvial, tanto en buen como en mal estado, son aquellos habitantes de las delegaciones Centro, Las Villas y Noroeste principalmente. Esta concepción indica que en estas delegaciones existen opiniones dispares y percepciones opuestas en relación con el estado del arroyo Napostá Grande y a su espacio fluvial. Sin embargo, en el caso de la representación espacial de las respuestas que perciben el área en buen estado los contrastes se evidencian de forma más notoria que en el caso de la espacialización de las respuestas que perciben el espacio fluvial en mal estado, que presentan mayor homogeneidad en la distribución de la densidad de respuestas y con frecuencias muy altas en la delegación Centro y Las Villas.

\section{FIGURA 10}

DENSIDAD NÚCLEO KERNEL DE RESPUESTAS QUE ALUDEN A LA PERCEPCIÓN DEL INDICADOR “MAL ESTADO" DEL ARROYO NAPOSTÁ GRANDE Y SU ESPACIO FLUVIAL

a)

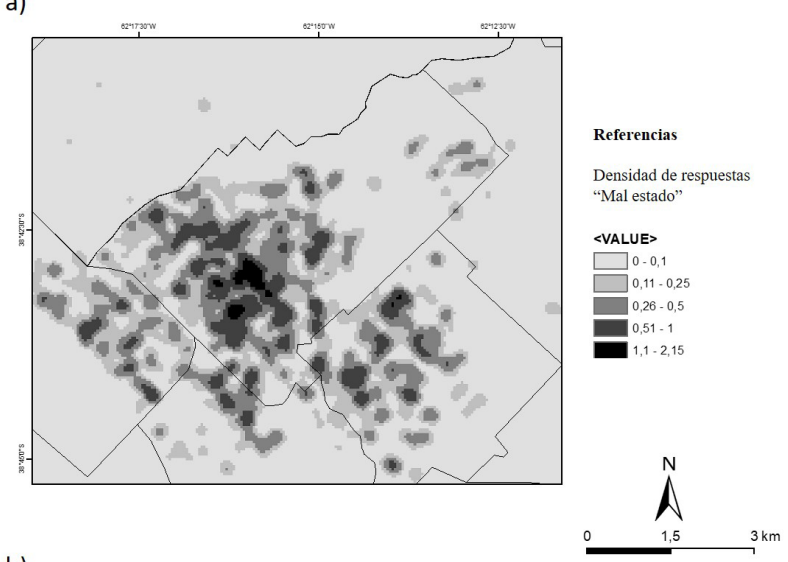

b)

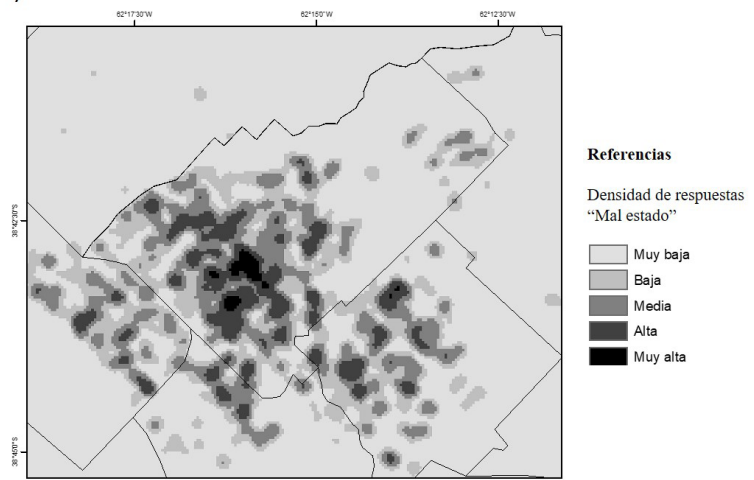

Fuente: elaboración propia sobre la base de los cuestionarios realizados.

\section{b) Problemas relacionados con el estado del cauce del arroyo Napostá Grande}

En relación con las densidades de las percepciones referidas a los problemas que se relacionan con el estado del cauce del arroyo Napostá Grande, se seleccionaron los indicadores: "vertidos domiciliarios e industriales" (429 casos, de los cuales 135 correspondieron a vertidos domiciliarios y 294 a industriales) y "mantenimien- 
to-limpieza y problemas sanitarios" (1178 casos, de los cuales 1039 correspondieron al inadecuado mantenimiento y limpieza y 139 a problemas sanitarios) por ser los principales conflictos percibidos por los habitantes de la totalidad de las delegaciones.

Con respecto al conflicto "vertidos domiciliarios e industriales" es posible observar una densidad sifnificativa en el microcentro de la ciudad y en determinados sectores de la delegación Las Villas, seguida de una densidad media, en el sector del macrocentro y en ciertas áreas puntuales de la delegación Noroeste. Este aspecto, expresa que los habitantes que viven en el sector céntrico de la ciudad, perciben que el espacio fluvial se encuentra degradado. Entre las razones que explican esta percepción, se encuentra la contaminación generada a partir de la actividad que las personas realizan cuando visitan frecuentemente el área como espacio recreativo y la actividad industrial que se desarrolla en el espacio local (figura 11).

FIGURA 11

DENSIDAD NÚCLEO KERNEL DE RESPUESTAS QUE ALUDEN A LA PERCEPCIÓN DEL PROBLEMA “VERTIDOS DOMICILIARIOS E INDUSTRIALES"

a)

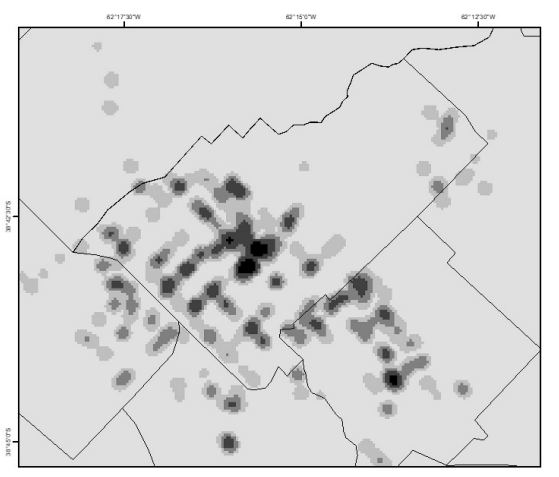

Referencias

Densidad de respuestas "vertidos domiciliarios industriales" SVALUE> $0-0,027$ $0,028-0,01$ $0,11-0,1$ 0.35-0.68

b)
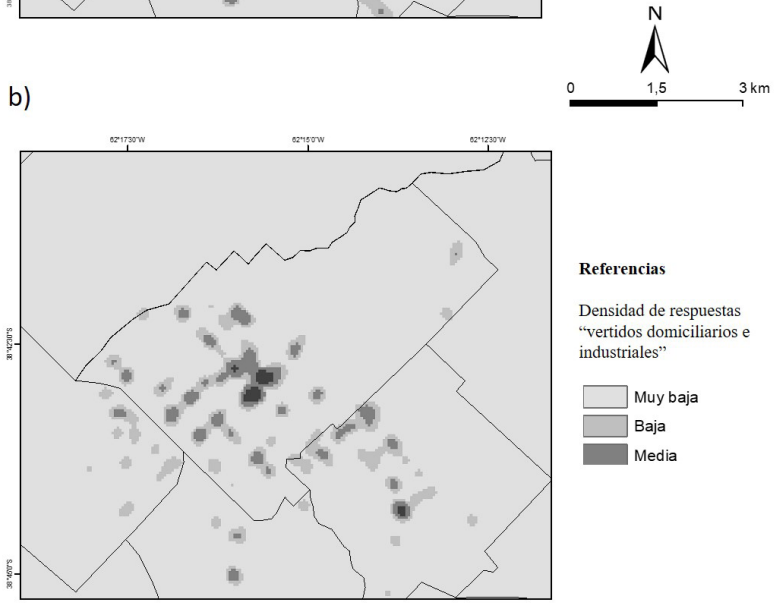

Fuente: elaboración propia sobre la base de los cuestionarios realizados.
Por su parte, con respecto al problema "inadecuado mantenimiento y limpieza" la densificación de las respuestas obtenidas es mayor y se distribuye de forma dispersa en la totalidad de las delegaciones, por lo que es un conflicto que una proporción significativa de las personas que viven en diferentes sectores de la ciudad percibe como prioritario. De este modo, en la cartografía realizada es posible observar una densidad muy alta en la delegación Centro, alta y media en las delegaciones Centro, Las Villas y Noroeste y muy baja y baja en el periurbano de la ciudad (figura 12).

FIGURA 12

DENSIDAD NÚCLEO KERNEL DE RESPUESTAS QUE ALUDEN A LA PERCEPCIÓN DEL PROBLEMA “INADECUADO MANTENIMIENTO Y LIMPIEZA"

a)

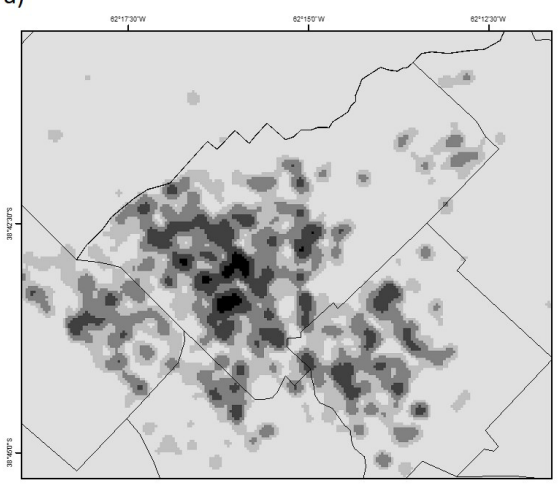

Referencias Densidad de respuestas "inadecuado $<$ VALUE $>$ $\square^{0-0,1}$ $0,11-0,25$
$0,26-0,5$ ]$_{1,1-1,77}^{0,51-1}$
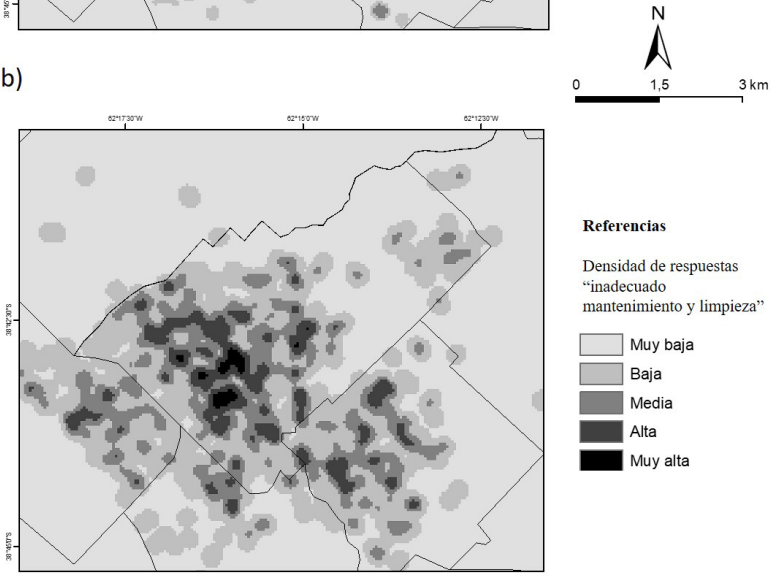

Fuente: elaboración propia sobre la base de los cuestionarios realizados.

\section{c) Percepción del arroyo Napostá Grande y su espacio circundante}

Al realizar un análisis de los resultados obtenidos a partir de la utilización de la técnica de densidad kernel con respecto al indicador de la percepción del arroyo como espacio degradado (714 casos) es posible identificar una distribución aproximadamente homogénea destacándose el caso de la delegación Centro en primera instancia, seguida de Las Villas y Noroeste. 
Asimismo, en la delegación Villa Rosas, Norte y Harding Green también se reconoce, aunque en menor proporción, la presencia de respuestas que consideran que el arroyo y su espacio fluvial circundante se encuentra deteriorado (figura 13).

De esta manera, la concepción generalizada del arroyo Napostá Grande y de su espacio fluvial como un sector deteriorado es una de las variables que deben tenerse en cuenta para planificar y gestionar el territorio en la elaboración de políticas públicas que contemplen la percepción de los ciudadanos de dichos sectores.

FIGURA 13

DENSIDAD NÚCLEO KERNEL DE RESPUESTAS QUE ALUDEN A LA PERCEPCIÓN SOCIAL DEL ARROYO NAPOSTÁ GRANDE COMO “ESPACIO DETERIORADO"

a)

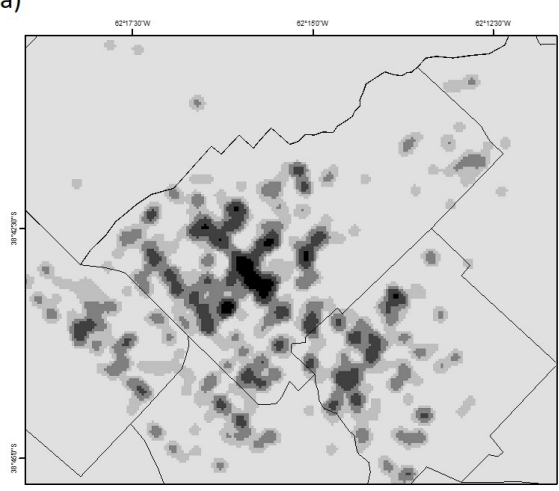
Densidad de respuestas "estado deteriorado" <VALUE> $\square 0.0,1$ $\square 0,11-0,25$ (10,20 0.5 $0,20-0,5$ $1,1 \cdot 2,15$
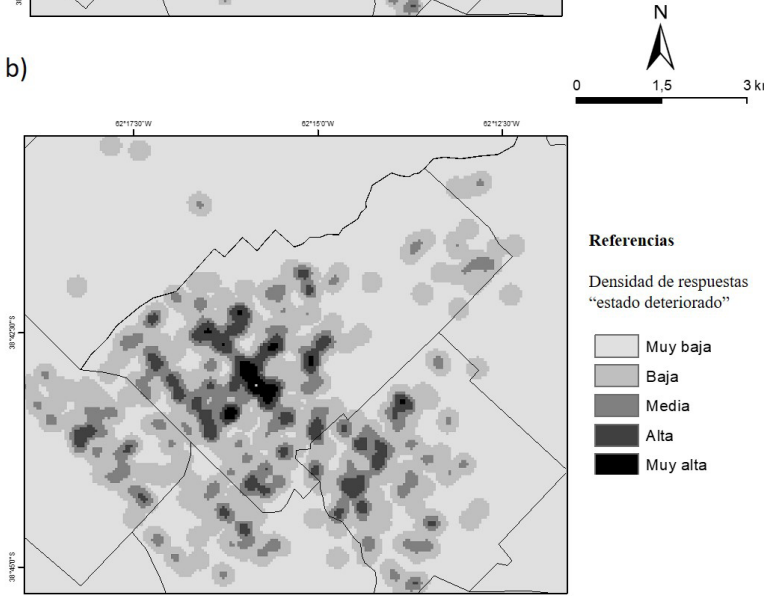

Fuente: elaboración propia sobre la base de los cuestionarios realizados.

Con el propósito de comparar los mapas realizados que aluden a los principales problemas percibidos con respecto al arroyo y a su espacio circundante, se ha efectuado una suma lineal de las capas reclasificadas con el método de intervalos de igualdad, correspondientes a: mal estado del arroyo, problemas vincu- lados con el inadecuado mantenimiento y limpieza; conflictos relacionados con vertidos domiciliarios e industriales y percepción social del arroyo como espacio degradado. El mapa síntesis, expresa la concentración espacial de las respuestas que aluden a la percepción negativa con el objetivo de considerar los sectores tendientes a una planificación en materia de gestión territorial.

En el mapa elaborado, es posible observar que la concentración de las respuestas que aluden a la percepción negativa del arroyo Napostá Grande y su espacio fluvial se localiza en aquellos sectores próximos al curso, especialmente en el sector sur de la delegación Centro. En este contexto, es importante destacar que, la suma de las percepciones negativas con respecto a los principales inconvenientes relacionados con el estado de deterioro del sector se encuentra presente, especialmente, en los habitantes que residen en las cercanías del arroyo. Por otro lado, los vecinos de las delegaciones Norte, Harding Green y Villa Rosas no tienen presente en sus imágenes mentales la noción de un espacio degradado debido a que no existe una concentración de respuestas en estas delegaciones. Entre las razones que pueden explicar este fenómeno se puede mencionar la lejanía al arroyo, la falta de conocimiento o, por el contrario, el desinterés en los problemas del sector. Finalmente, en el caso de las delegaciones Las Villas $y$, en menor medida, Noroeste se identifica una densidad de respuestas moderada.

En suma, las percepciones diferenciales de los habitantes de las delegaciones analizadas proporcionan un conocimiento valioso para la gestión de los problemas que inciden en el desarrollo de sus actividades cotidianas. La consideración de los problemas socialmente percibidos y su espacialización colabora en la planificación del espacio urbano incluyendo la participación de la población local como una herramienta eficaz de gestión y ordenamiento territorial.

\section{Discusıón}

El estudio, proporciona información geolocalizada sobre la percepción social que los habitantes de la ciudad de Bahía Blanca presentan del arroyo Napostá Grande, de su espacio fluvial como así también, de los problemas más representativos relacionados con su estado de conservación. Esta información es valiosa para la planificación y gestión territorial tomando como base la participación de la población. 


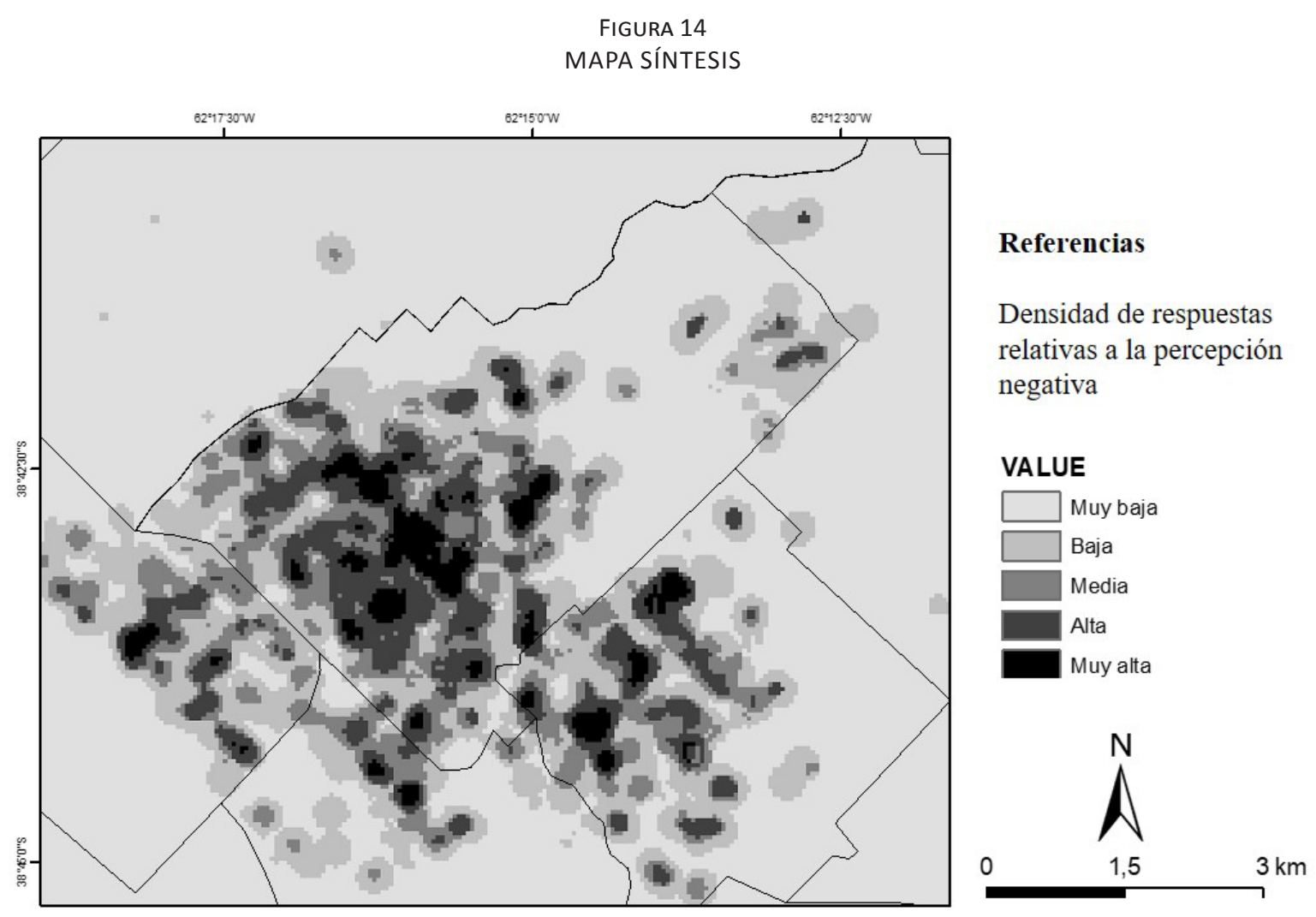

Fuente: elaboración propia sobre la base de los cuestionarios realizados.

Teniendo en cuenta las investigaciones que han incorporado los Sistemas de Información Geográfica de Participación Pública (SIGPP) se destacan los estudios de Goodchild (2007) quien utiliza los SIG para analizar patrones espaciales de la densidad de población en Seúl a través de aplicaciones para teléfonos inteligentes que presentan servicios basados en la ubicación (LBSN). De este modo, la geolocalización de los lugares frecuentados para analizar sus propiedades de distribución espacial dentro de una ciudad ha sido utilizado como insumo para analizar información geoespacial y gestionar el espacio urbano. Por su parte Brown y Reed (2012), a través de la técnica de métricas del paisaje, cuantifican las percepciones de la sociedad mediante el uso de los Sistemas de Información Geográfica de Participación Pública (SIGPP). Asimismo, Alessa, Kliskey y Brown (2008) mapean Sistemas Socio Ecológicos (SES) vinculando la técnica de la encuesta y los SIG con el propósito de brindar representaciones espaciales de la interrelación entre los sistemas sociales y ecológicos. De este modo, el vínculo que se establece entre la información recopilada en las encuestas y la evaluación y espacialización de la percepción en un SIG permite implementar los SIGPP y crear, analizar y difundir información geográfica como soporte en la toma de decisiones.

Es importante destacar que, en el estudio, una debilidad de la técnica IVR, radica en la consideración de la totalidad de los domicilios sin discriminar los teléfonos fijos que no corresponden a una vivienda, motivo por el cual, la información obtenida puede corresponder a locales, oficinas y establecimientos de diversa índole. Otra dificultad de la técnica radica en que la totalidad de las respuestas obtenidas varía en función de cada interrogante debido a que no todas las personas encuestadas han contestado la misma cantidad de preguntas, razón por la cual, se ha incorporado un mapa a través de la utilización de intervalos de igualdad para asemejar los valores de los intervalos. Además, es importante mencionar que el gran volumen de información recopilada impidió analizar la totalidad de las respuestas del cuestionario, tal es el caso de la pregunta 1 y 5 , motivo por el cual, su abordaje se considera relevante para la profundización del estudio en posteriores investigaciones. 
Sin embargo, el trabajo resulta enriquecedor dado que, los resultados pueden analizarse en función de la manifestación espacial de cada interrogante y utilizarse como base para una planificación de participación pública más eficaz. En este sentido, a través de las técnicas empleadas, se recopiló un gran volumen de información y se procesó en un período de tiempo relativamente corto, a la vez que posibilitó realizar un mapa final síntesis con los sectores en los que coincide la percepción social de diferentes problemas.

De lo expuesto, se destaca la complejidad que reviste llevar a cabo estudios que involucran la percepción de fenómenos sociales a través de técnicas cuantitativas como las TIC's y TIG's y la dificultad de espacializar y analizar las concepciones construidas por los habitantes de los problemas que enfrentan en su vida diaria. De este modo, la presente investigación constituye un abordaje que será utilizado como punto de partida para la realización de futuras investigaciones con el propósito de seguir profundizando el análisis de la percepción social del espacio fluvial.

\section{CONCLUSIONES}

En el área de estudio, los habitantes del espacio urbano perciben su entorno más próximo, como así también los problemas cotidianos que enfrentan, de un modo particular que se encuentra ligado al contexto social e histórico de la comunidad local Asimismo, la percepción del estado de conservación del arroyo Napostá Grande, como así también la identificación de los problemas relacionados con el estado del curso y su espacio circundante remite a diversos factores entre los que se destacan la proximidad con el arroyo, los vínculos establecidos con espacio fluvial y los problemas ambientales acontecidos en el sector, entre otros aspectos.

En este contexto, conocer la percepción que los vecinos de la ciudad de Bahía Blanca tienen respecto del arroyo y de su espacio fluvial permite analizar las necesidades de la población local, información que será relevante para la toma de decisiones. Por su parte, los SIG ofrecen la posibilidad de generar una base de referencia de gran utilidad para el establecimiento de diversas propuestas de gestión del espacio en el corto, mediano y largo plazo a fin de promover un desarroIlo sustentable, sostenible y un uso responsable del espacio fluvial.

De este modo, a través del análisis efectuado es posible reconocer que, con respecto a la percepción del curso y su espacio circundante, la imagen colectiva construida es la de un lugar degradado que requiere de tareas de limpieza y mantenimiento. Sin embargo, para otros vecinos de la ciudad, representa un espacio de recreación y el arroyo constituye un elemento significativo del espacio urbano. Estas diferencias con respecto a la percepción social del mencionado curso fluvial y de su espacio circundante manifiestan la incidencia que diversos factores tienen con respecto a la construcción de las imágenes mentales elaboradas por los vecinos de la ciudad en su percepción del espacio más próximo. Así, por ejemplo, es notable observar la presencia de un elevado número de respuestas en los cuestionarios realizados que no expresan un conocimiento de los problemas que se relacionan con el arroyo, como sucede en el caso de la delegación de Villa Rosas. Este hecho demuestra la ausencia de dicho elemento en las construcciones de las imágenes que los vecinos elaboran del espacio urbano y de sus elementos que puede asociarse con factores de distancia y proximidad. Por su parte, también se identifica una mayor densidad de respuestas en las delegaciones Centro, Las Villas y Noroeste. Esta representación, podría relacionarse con el grado de proximidad al arroyo y a su espacio fluvial como sector de recreación y de desarrollo de prácticas cotidianas.

En este sentido, las técnicas cuantitativas constituyen herramientas enriquecedoras para evaluar y analizar la percepción social que tienen los habitantes del espacio urbano del estado de conservación y uso del arroyo Napostá Grande. Se reconoce la importancia y la necesidad de utilizar las TIC's y TIG's para espacializar cuestiones relacionadas con la percepción del estado del arroyo, de su espacio circundante, de los usos y de los principales problemas relacionados con el mismo. La riqueza derivada de la espacialización de las respuestas obtenidas permite identificar las diferentes percepciones sociales de los habitantes según la delegación de residencia, conocimiento que colabora en la elaboración de políticas y en la planificación y gestión del espacio urbano.

\section{AgRADECIMIENTOS}

Los autores agradecen especialmente los comentarios y sugerencias de los evaluadores que otorgaron mayor solidez al estudio. La presente investigación se realizó en el marco de subsidios otorgados por la Comisión de Investigaciones Científicas $(\mathrm{CIC})$ y la Universidad Nacional del Sur (UNS). 


\section{BibLIOgRAFÍA}

Alessa, L., Kliskey, A., y Brown, G. (2008). Socialecological hotspots mapping: a spatial approach for identifying coupled social-ecological space. Landscape and Urban Planning, 85(1), 27-39. Recuperado de: http://www.landscapevalues.org/ publications/landscape_urban.pdf

Assef, L. (2013). Sistemas de análisis de sentimientos en Twitter para el idioma español (Tesis de grado). Universidad Nacional del Sur, Bahía Blanca.

Bosque Sendra, J. (2001). Planificación y gestión del territorio. De los SIG a los sistemas de ayuda a la decisión espacial (SADE). El campo de las Ciencias y las Artes, 138, 137-174. Recuperado de: https:// geogra.uah.es/joaquin/pdf/SIG-y-SADE.pdf

Brown, G., y Reed, P. (2012). Social landscape metrics: measures for understanding place values from Public Participation Geographic Information Systems (PPGIS). Landscape Research, 37(1), 73-90. https://doi.org/10.1080/01426397.2011.591487

Buzai, G. D. (2001). Paradigma geotecnológico, geografía global y cibergeografía, la gran explosión de un universo digital en expansión. Geofocus, Revista Internacional de Ciencia y Tecnología de la Información Geográfica, 1, 24-48. Recuperado de: http://geofocus.rediris.es/docPDF/Articulo3_2001.pdf

Carrica, J. (1998). Hidrología de la cuenca del arroyo Napostá Grande, provincia de Buenos Aires (Hidrogeology of arroyo Napostá Grande basin). (Tesis de posgrado). Universidad Nacional del Sur, Bahía Blanca.

Denzin, N. K. (2009). The Research Act: a theoretical introduction to Sociological Methods. https://doi. org/10.4324/9781315134543

Dobson, J. E. (1993). The geographic revolution: A retrospective on the age of automated geography. The Professional Geographer, 45(4), 431-439.

Dodge, M., Kitchin, R y Perkins, C. (eds.) (2011). The Map Reader: Theories of Mapping Practice and Cartographic Representation, London, Routledge, $504 \mathrm{pp}$

Gaitán Moya, J. A. y Lozano Ascencio, C. (2013). Triangulación en el análisis de la representación social del cambio climático. En M. V. Mariño, T. González Hortigüela, M. Pacheco Rueda. (Coord), Investigar la Comunicación hoy. Revisión de políticas científi- cas y aportaciones metodológicas: Simposio Internacional sobre Política Científica en Comunicación (pp. 599-614). Segovia, España: Universidad de Valladolid, Facultad de Ciencias Sociales, Jurídicas y de la Comunicación.

García Ballesteros, A. y Bosque Sendra, J. (1989). El espacio subjetivo de Segovia. Madrid, España: Editorial Universidad Complutense.

Gómez Mendoza, J., Muñoz Gimenez, J., Ortega Cantero, N. (1982): El pensamiento geográfico. Madrid, Alianza Universidad, 272 pp.

Goodchild, M. (2007). Citizens as voluntary sensors: spatial data infrastructure in the world of web 2.0. International Journal of Spatial Data Infrastructures Research, 2, 24-32.

Instituto Nacional de Estadísticas y Censos (INDEC) (2010). https://www.indec.gov.ar/ (Fecha de consulta: $2 / 11 / 17)$.

Lindon, A. y Hiernaux, D. (2006). Tratado de Geografía Humana. México, Antrophos, Universidad Autónoma Metropolitana, $652 \mathrm{pp}$.

Moreno Jiménez, A. y Fuenzalida Díaz, M. (2017). Medición y cartografía del impacto socialmente percibido ante industrias contaminantes con $u$ estimador de densidad núcleo (kernel) y SIG: aplicación al caso del complejo industrial Ventanas, Chile. Estudios Geográficos, 78(282), 225-256.

Palacio Buendía, A. V. (2017). Análisis de percepción en la gestión de espacios naturales y el uso de sistemas de información geográfica de participación pública. Tesis de Doctorado en Geografía, Universitat Rovira i Virgili, 328 pp.

Prieto, M.B. (2013). Diferenciación socio-espacial y condiciones de vida en Bahía Blanca (1991-2011). Hologramática, 1(18), 43-72. Recuperado de: http://cienciared.com.ar/ra/usr/3/1442/hologramatica_n18v1pp43_72.pdf

Santamaría, M. y Aldalur, B. (2014). Enfoque estadístico de análisis de textura: su aplicación a la clasificación de un ortofotomosaico del valle de inundación del arroyo Napostá Grande. Revista Internacional de Ciencia y Tecnología de la Información Geográfica Geofocus, 14, 55-67.

Santos, M. (1990). Por una Geografía nueva. Madrid, España: Espasa Calpe. 
Silverman, B. W. (1986). Density estimation for statistics and data analysis. Londres: Chapman and Hall.
Vieytes, R. (2004). Metodología de la investigación en organizaciones, mercado y sociedad. Epistemología y técnicas. Buenos Aires, Argentina: De las Ciencias.

\section{ANEXO}

Modelo de cuestionario para vecinos de la ciudad de Bahía Blanca

Este cuestionario, de carácter anónimo, tiene como propósito conocer la percepción social del riesgo hídrico que tienen los habitantes de la ciudad de Bahía Blanca. La información será de suma utilidad para realizar un trabajo de investigación en el Departamento de Geografía y Turismo de la UNS.

1. ¿Considera que su barrio tiene/ha tenido problemas de inundaciones y/o anegamientos?

- Sí (presione 1) -No (presione 2)

En caso de respuesta afirmativa:

1.1. ¿Cuáles de los siguientes aspectos cree que profundiza el problema de inundaciones y anegamientos en su barrio?

- Estado/mantenimiento de los desagües pluviales (presione 1)

- Problemas en las napas del suelo (presione 2)

- Ubicación en zonas inundables (presione 3)

- Crecimiento espontáneo de la ciudad (presione 4)

- Desborde del arroyo (presione 5)

2. ¿Cuál cree que es el estado del arroyo Napostá Grande y su espacio circundante?

- Muy Bueno (presione 1)

- Bueno (presione 2)

- Regular (presione 3)

- Malo (presione 4)

-No sabe (presione 5)
3. ¿Cuál cree que es el principal problema relacionado al estado del cauce del arroyo Napostá Grande?

- Vertidos domiciliarios (presione 1)

- Vertidos industriales (presione 2)

- Inadecuado mantenimiento y limpieza (presione 3)

- Problemas sanitarios (presione 4)

- No sabe (presione 5)

4. ¿Cuál es su percepción acerca del arroyo Napostá en la ciudad de Bahía Blanca?

- Lugar de paso (presione 1)

- Elemento significativo de la ciudad (presione 2)

- Espacio de recreación/ocio (presione 3)

- Espacio degradado/deteriorado (presione 4)

- No sabe (presione 5)

5. ¿Qué usos se le podrían dar al arroyo Napostá en la ciudad?

- Recreativo (presione 1)

- Utilización de agua para riego (presione 2)

- Abastecimiento de agua para industria (presione 3)

- No sabe (presione 4) 